This document is the accepted manuscript version of the following article:

Armbrüster, M., Behrens, M., Cinquini, F., Föttinger, K., Grin, Y., Haghofer, A., ... Wowsnick, G. (2012). How to control the selectivity of palladium-based catalysts in hydrogenation reactions: the role of subsurface chemistry. Chemcatchem, 4(8), 1048-1063.

https: //doi .org/10.1002/cctc. 201200100

\title{
How to control the selectivity of palladium- based catalysts in hydrogenation reactions: The role of subsurface chemistry
}

\author{
Marc Armbrüster ${ }^{[a]}$ Malte Behrens, ${ }^{*[b]}$ Fabrizio Cinquini, ${ }^{[c]}$ Karin Föttinger ${ }^{[d]}$ Yuri \\ Grin, ${ }^{\left[{ }^{[a]}\right.}$ Andreas Haghofer, ${ }^{[\mathrm{d}]}$ Bernhard Klötzer, ${ }^{[\mathrm{e}]}$ Axel Knop-Gericke, ${ }^{[\mathrm{b}]}$ Harald \\ Lorenz, ${ }^{[\mathrm{e}]}$ Antje Ota, ${ }^{[\mathrm{b}]}$ Simon Penner, ${ }^{[\mathrm{e}]}$ Jan Prinz, ${ }^{[\mathrm{fl}}$ Christoph Rameshan, ${ }^{[\mathrm{b}],[\mathrm{e}]}$ Zsolt \\ Révay, ${ }^{\left[{ }^{[g]}\right.}$ Dirk Rosenthal, ${ }^{[\mathrm{b}]}$ Günther Rupprechter ${ }^{[\mathrm{d}]}$ Philippe Sautet, ${ }^{[\mathrm{c}]}$ Robert \\ Schlögl ${ }^{[b]}$ Lidong Shao, ${ }^{[b]}$ László Szentmiklósi, ${ }^{\left[{ }^{[b]}\right.}$ Detre Teschner, ${ }^{[b]}$ Daniel \\ Torres, ${ }^{[c]}$ Ronald Wagner, ${ }^{[b]}$ Roland Widmer, ${ }^{[f]}$ Gregor Wowsnick ${ }^{[b]}$
}

This paper reviews recent experimental and theoretical results on palladium-based catalysts in selective hydrogenation of alkynes obtained by a number of collaborating working groups in a joint multimethod and multi-material approach. The critical modification of catalytically active $\mathrm{Pd}$ surfaces by incorporation of foreign species $X$ in the sub-surface of Pd metal was observed by in situ spectroscopy for $X=\mathrm{H}, \mathrm{C}$ under hydrogenation conditions. Under certain conditions (low $\mathrm{H}_{2}$ partial pressure) alkyne fragmentation leads to formation of a $\mathrm{Pd}-\mathrm{C}$ surface phase in the reactant gas feed. The insertion of $\mathrm{C}$ as a modifier species in the sub-surface considerably increases the selectivity of alkyne semi-hydrogenation over Pd-based catalysts by decoupling of bulk hydrogen from the outmost active surface layer. DFT calculations confirm that $\mathrm{Pd}-\mathrm{C}$ hinders the diffusion of hydridic hydrogen. Its formation is dependent on the chemical potential of

\section{Introduction}

$\mathrm{Pd}$ is a widely used element in the field of heterogeneous catalysis, which is active in many reactions, among them the industrially important semi-hydrogenation of alkynes. This reaction, which serves as a model reaction for the present study, is applied in course of industrial polymerization of ethylene to polyethylene (ca. 50 Megatons/year) to purify the feedstock from acetylene, which would otherwise poison the downstream

[a] Dr. Marc Armbrüster, Prof. Dr. Yuri Grin

Max-Planck-Institut für Chemische Physik fester Stoffe

Nöthnitzer Str. 40, D-01187 Dresden, Germany

[b] Dr. Malte Behrens, Antje Ota, Dr. Axel Knop-Gericke, Dr. Christoph Rameshan, Dr. Dirk Rosenthal, Prof. Dr. Robert Schlögl, Dr. Lidong Shao, Dr. Detre Teschner, Dr. Ronald Wagner, Gregor Wowsnick Department of Inorganic Chemistry

Fritz-Haber-Institut der Max-Planck. Gesellschaft

Faradayweg 4-6, D-14195 Berlin, Germany

Fax: (+) 493084134405

E-mail: behrens@fhi-berlin.mpg.de

[c] Dr. Fabrizio Cinquini, Prof. Dr. Philippe Sautet, Dr. Daniel Torres Université de Lyon, CNRS

Institut de Chimie de Lyon, Ecole Normale Supérieure de Lyon 46 allée d'Italie, F-69364 Lyon Cedex 07, France carbon (reactant partial pressure) and is suppressed when the hydrogen/alkyne pressure ratio is high leading to rather unselective hydrogenation over in situ formed bulk $\mathrm{Pd}-\mathrm{H}$. The beneficial effect of the modifier species $X$ on the selectivity, however, is also present in intermetallic compounds with $X=\mathrm{Ga}$. As a great advantage, such $\mathrm{Pd}_{\mathrm{x}} \mathrm{Ga}_{\mathrm{y}}$ catalysts show extended stability under in situ conditions. Metallurgical, clean samples were used to determine the intrinsic catalytic properties of $\mathrm{PdGa}$ and $\mathrm{Pd}_{3} \mathrm{Ga}_{7}$. For high performance catalysts, supported nanostructured intermetallic compounds are more preferable and partial reduction of $\mathrm{Ga}_{2} \mathrm{O}_{3}$ upon heating of $\mathrm{Pd} / \mathrm{Ga}_{2} \mathrm{O}_{3}$ in hydrogen was shown to lead to formation of $\mathrm{Pd}-\mathrm{Ga}$ intermetallic compounds at moderate temperatures. In this way, $\mathrm{Pd}_{5} \mathrm{Ga}_{2}$ and $\mathrm{Pd}_{2} \mathrm{Ga}$ are accessible in form of supported nanoparticles, in thin film models and realistic powder samples, respectively. polymerization catalyst. The acetylene content has to be lowered from usually around $1 \%$ to the low ppm range. Hence, the requirements for the hydrogenation catalyst are to effectively convert acetylene in an excess of ethylene to protect the polymerization catalyst and to do this at highest possible selectivity avoiding total hydrogenation of acetylene to maximize the final polyethylene yield. Thus, selectivity is of utmost importance in the field of Pd-based semi-hydrogenation catalysts and the problem how to understand variations in selectivity of $\mathrm{Pd}$ based catalysts is academically appealing as well as of very high

\footnotetext{
[d] Dr. Karin Föttinger, Dr. Andreas Haghofer, Prof. Dr. Günther Rupprechter Institute of Materials Chemistry

Vienna University of Technology

Getreidemarkt 9/BC/01, A-1060 Vienna, Austria

[e] Assoz. Prof. Dr. Bernhard Klötzer, Mag. Harald Lorenz, Priv. Doz. Mag. Dr. Simon Penner, Dr. Christoph Rameshan Institute of Physical Chemistry

University of Innsbruck

Innrain 52A, A-6020 Innsbruck, Austria

[f] Jan Prinz, Roland Widmer

nanotech@surfaces

Empa - Swiss Federal Laboratories for Materials Science and Technology

Ueberlandstrasse 129, CH-8600 Duebendorf, Switzerland

[g] Dr. Zsolt Révay, Dr. László Szentmiklósi

Nuclear Analysis and Radiography Department

Centre for Energy Research, Hungarian Academy of Sciences

P.O. Box 49, $\mathrm{H}-1525$ Budapest 114, Hungary
} 
industrial interest. It has triggered much fundamental work in the past and present, recently reviewed by Borodziński and Bond $[1,2]$.

The group at the Fritz-Haber-Institute started to study the question - which factors influence the selectivity of Pd-based catalysts and how it can be controlled - in 2002, first in the framework of the ATHENA project ${ }^{i}$ and presently in a loose consortium of European research groups, who contribute their complementary views on this problem. This paper is intended to review the results obtained within this very fruitful collaboration and provides insights into $\mathrm{Pd}$-based catalytic materials from spectroscopic characterization, quantum chemical calculations, reactivity studies and synthesis.

The question why Pd, which is a very active catalyst in the hydrogenation of alkenes to alkanes, can under certain conditions selectively hydrogenate triple bonds and stop at the stage of the double bond, is, of course, not new and numerous views can be found in the literature. One early explanation is the difference in heat of adsorption, which favors desorption of the partially hydrogenated intermediate [ 3 ]. It was, however, shown experimentally that ethylene can adsorb on distinct sites on the surface of $\mathrm{Pd}$ catalysts in the presence of acetylene [4]. Furthermore, the role of sub-surface or even bulk-hydrogen (formation of the $\beta$-palladiumhydride phase) seems to be of importance. It was shown experimentally [5] and theoretically $[6,7]$ that hydrogen dissolved in metals can diffuse to the surface and hydrogenate adsorbates. Compared to surface-adsorbed hydrogen, subsurface-hydrogen species were found to disfavor selective partial hydrogenation by enhancing undesired total hydrogenation [8]. Weakly absorbed bulk-hydrogen was recently reported to be responsible for olefin hydrogenation over $\mathrm{Pd}$ nanoparticles and it was suggested that carbonaceous deposits favor the regeneration of the involved hydrogen species [9].

In addition, Pd alloys are seen as an example of the so-called active site isolation concept, which is mainly based on geometric considerations. Isolation of surface $\mathrm{Pd}$ atoms by spatial separation is suggested to reduce the surface concentration of the di- $\sigma$-adsorbed ethylene, which takes place on neighboring sites forming ethylidyne and vinylidene species strongly bound to the surface [10-12]. These species may oligomerize, act as precursors for carbonaceous deposits hence cause deactivation and decrease the ethylene yield. Oligomerization has been found to be an important issue for the stability and selectivity of monometallic Pd catalysts but also to other hydrogenation metals like $\mathrm{Cu}$ or even $\mathrm{Au}$ [13]. According to DFT simulations, high carbon formation energy and low alkyne binding energy was obtained to scale with low oligomerization barrier in propynepropyne coupling [13]. Oligomerization on $\mathrm{Pd}$ was essentially not observed without $\mathrm{H}_{2}$ and was found to decrease with increasing $\mathrm{H}_{2} / \mathrm{C}_{2} \mathrm{H}_{2}$, [14] and hence an optimal $\mathrm{H}_{2}$ pressure range exists that facilitate this side reaction. $\mathrm{CO}$ feeding was shown to effectively moderate total hydrogenation of alkynes, nevertheless oligomerization selectivity strongly increased upon increasing $\mathrm{CO}: \mathrm{H}_{2}$ feed ratios [15]. DFT calculations by Garcia-Mota et al.

Research project "Advanced Technology in Catalytic Chemistry and Engineering for Novel Applications" (ATHENA) was a 5-year-long international project aiming to gain a fundamental understanding of the relationship between catalyst properties under reaction condition and selectivity in various

heterogeneously catalyzed reactions in the field of hydrogenation,

dehydrogenation and oxidation.
[13] indicated that in the presence of subsurface carbon, the barrier for $\mathrm{C}-\mathrm{C}$ coupling increased significantly compared to clean $\mathrm{Pd}$, whereas $\mathrm{CO}$ feeding reduced the barrier. In addition to the role of Pd surfaces, the support is often reported to contribute in ethylene oligomerization. Carbonaceous deposits separate the active surface sites and reduce their size by surface blocking, which strongly affects the catalytic properties $[1,16]$. Furthermore, the supply of hydrogen to the surface and sub-surface will be decreased by the absence of neighboring sites, thus changing selectivity $[15,17]$ as well as catalyst stability. These considerations can also explain the benefit of employing Pd-Ag alloys rather than pure $\mathrm{Pd}$ catalysts in industrial semihydrogenation, which exhibit superior selectivity [3] and stability. The presence of $\mathrm{Ag}$ lowers the surface concentration of Pd and, thus, effectively reduces the average size of the active ensembles [18]. Another interpretation of the beneficial effect of $\mathrm{Ag}$ has been reported by Studt et al. [19], who calculated the potential energy diagram of the hydrogenation of acetylene over pure $\mathrm{Pd}$ and a $\mathrm{PdAg}$ catalyst. They found that the addition of $\mathrm{Ag}$ lowers the energy barrier of desorption of the intermediately formed ethylene with respect to the energy barrier of further hydrogenation to ethane and thus makes the catalyst more selective. The same group also pointed out that similar effects are also present in case of other modifying atoms in the subsurface of Pd like carbon [13]. Other groups have recently reported similar results $[15,20]$ and role of promoters has been recently reviewed by López and Vargas-Fuentes [21].

Our recent results on pure $\mathrm{Pd}$ samples, which will be reviewed in this paper, strongly support the idea that the fresh $\mathrm{Pd}$ catalyst is modified under reaction conditions as a function of the reactant partial pressures in the feed not only by surface deposits but also by sub-surface species. Such modifications make the newly formed $\mathrm{Pd}-X$ surface phase $(X=\mathrm{C}, \mathrm{H})$ the actual catalyst for hydrogenation and are responsible for a dramatic change in selectivity - an increase in case of $X=C$ and a decrease for $X=$ $H$. This insight inspired our later works focused on more directed and controlled preparation of $\mathrm{Pd}-X(X=\mathrm{Ga})$ catalysts and characterization of their structural stability and catalytic properties.

This paper is organized as follows: Firstly, results obtained on pure Pd model catalysts in various alkyne feeds and the decisive role of the $\mathrm{Pd}-\mathrm{C}$ surface phase will be discussed. These results will then be complemented by theoretical calculations, and subsequently, the replacement of carbon by metal atoms and the effect on the material's and catalytic properties will be described. Unsupported bulk model catalysts of Pd-Ga intermetallic phases and their activity and selectivity in gas and liquid phase hydrogenation reactions are treated afterwards. Then, single crystals surface studies of PdGa will be presented followed by a discussion of, nano-particulate thin film models of $\mathrm{Pd}-X$ catalysts $(X=\mathrm{Ga}, \mathrm{Zn}, \mathrm{Si})$ and powder $\mathrm{Pd}-\mathrm{Ga} / \mathrm{Ga}_{2} \mathrm{O}_{3}$ systems with a focus on the role of the oxide support. Finally, the presented results will be put in a generic perspective before a conclusion and outlook will be given at the end of the paper. We note that according to the IUPAC recommendations 2005 [22] and due to consistency with the previous literature the intermetallic compound is named in this review PdGa instead of GaPd.

\section{The surface of monometallic Pd catalysts under hydrogenation}


Utilizing synchrotron radiation and differential pumping, nowadays it is possible to investigate the surface electronic structure of materials by XPS under catalytic turnover. First [23] we studied the hydrogenation of 1-pentyne over supported and unsupported $\mathrm{Pd}$ materials and observed that partial hydrogenation was the dominant reaction path at the reduced pressure condition of few mbar applied during XPS experiments. Moreover, the reaction was accompanied by the build-up of a surface $\mathrm{Pd}-\mathrm{C}$ phase, via fragmentation of reactant molecules and carbon dissolving in the top few Pd layers. This was identified by the $\sim 335.5 \mathrm{eV} \mathrm{Pd} 3 \mathrm{~d}$ component; its contribution to the overall Pd $3 d$ envelop strongly exceeding the limit of surface core level shift component of hydrocarbonaceous adsorbates. Additionally, the low binding energy $\mathrm{C} 1 \mathrm{~s}$ component $(283.4 \mathrm{eV})$, being close to those of carbides, substantiated the assignment of carbon occupying subsurface positions. By performing non-destructive depth profiling via photon energy variation, we concluded that the $\mathrm{Pd}-\mathrm{C}$ phase was 2-3 atomic layer thick. Thus the Pd-C surface phase defines the top few Pd layers with subsurface carbon participation. Later [ 24,25$]$, we have generalized these observations (Fig. 1), as other alkynes were also shown to react in partial hydrogenation on a carbon modified $\mathrm{Pd}$ surface, whereas alkenes never induced such surface modification. Note, when acetylene was hydrogenated (Fig. 1F) the new Pd 3d component was much more enhanced and hence the $\mathrm{Pd}-\mathrm{C}$ layer was thicker than mentioned above. When studying the temporal evolution of Pd-C, we observed a two step process: a fast initial C uptake likely related to the occupation of the first subsurface sites, and a second slow process of further growth of Pd-C. We show that by applying a high hydrogen/alkyne pressure ratio the alkyne total hydrogenation starts to be the prevailing reaction path. This can be correlated to the vanishing $\mathrm{Pd}-\mathrm{C}$ component at higher $\mathrm{H}_{2} / \mathrm{C}_{5}$ ratios [24]. Therefore we concluded that alkynes are selectively hydrogenated on $\mathrm{Pd}-\mathrm{C}$, whereas unselective alkyne hydrogenation as well as alkene hydrogenation proceeds on $\mathrm{Pd}$ surfaces without subsurface $C$ modification. Changes in the selectivity pattern with variation of the hydrogen-to-hydrocarbon ration have also been observed for hydrogenation of polyunsaturated substrates over Pd-based catalysts [26].

The quantification of surface hydrogen concentration under hydrogenation conditions is extremely challenging (if possible at all), and hence there is no clear description in the literature about the way hydrogen changes hydrogenation selectivity quite abruptly. By measuring the bulk hydrogen content of $\mathrm{Pd}$ under different hydrogenation conditions utilizing in situ Prompt Gamma Activation Analysis (PGAA) [27] we tried to correlate the bulk hydrogen content with the activity and reaction selectivity, on the assumption that bulk is equilibrated with the surface under steady state hydrogenation conditions. Figure 2 shows one experiment, in which we compare the conversion of 1-penyne hydrogenation (selectivity is higher than $95 \%$ toward pentene formation) and the corresponding bulk hydrogen content at the same experimental conditions, however at different stages of a long-term (several days long) measurement. It is strikingly obvious that there is no correlation between activity in the regime of selective hydrogenation and the amount of hydrogen dissolved in palladium. Furthermore, selective partial hydrogenation is compatible with both, high ( $\beta$-palladiumhydride) and low bulk hydrogen concentration. This indicates that there should be a mechanism (involving $\mathrm{Pd}-\mathrm{C}$ ) that decouples the rate of steady state hydrogenation from the bulk hydrogen content.
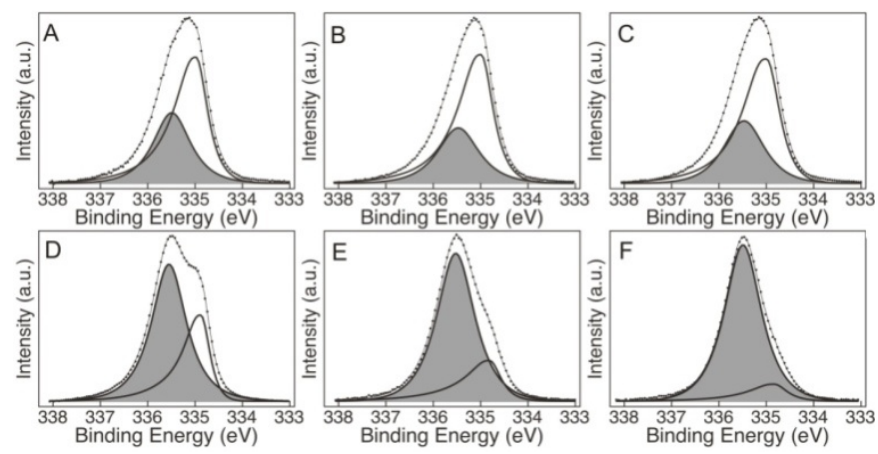

Figure 1: Comparison of in situ $\mathrm{Pd} 3 \mathrm{~d}_{5 / 2}$ spectra of $\mathrm{Pd}$ foil under alkene and alkyne hydrogenation at $1 \mathrm{mbar}\left(\mathrm{H}_{2} / \mathrm{C}_{\mathrm{x}} \mathrm{H}_{\mathrm{y}}\right.$ : 9/1) and 343-353 K. A: 1-pentene; B: propene; C: ethylene; D: 1-pentyne; E: propyne; F: acetylene.

Additional hydrogenation experiments at total alkyne hydrogenation as well as with alkenes indicate that the bulk exists exclusively in hydride form, underlining the missing decoupling mechanism in these cases. Recent in situ PGAA experiments [28] with $\mathrm{H} / \mathrm{D}$ exchange show that hydrogen can diffuse through the $\mathrm{Pd}-\mathrm{C}$ layers but this process, as estimated by theory, is significantly slowed down due to the increased diffusion barrier (see also next section).

In summary, in situ observations clearly showed the formation of a Pd-C sub-surface phase associated with selective hydrogenation of alkynes. The superior selectivity of this in situ formed catalytic phase seems to be due to a decoupling of the bulk hydride phase from the outmost active surface layer, hindering the supply of hydrogen from the subsurface and below.
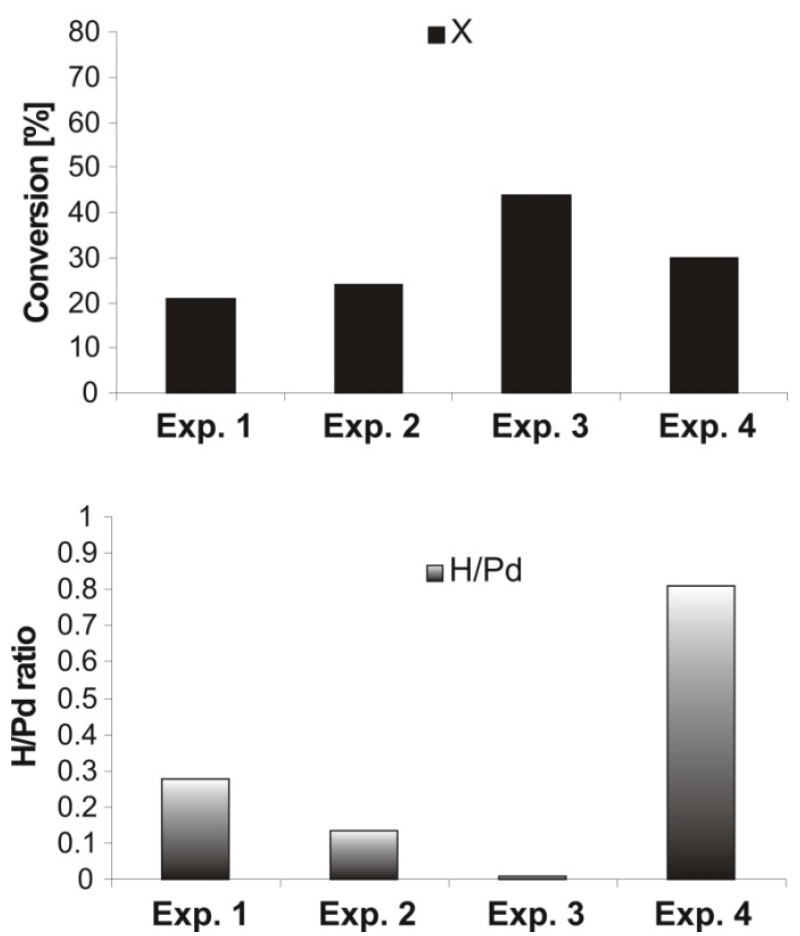

Figure 2: 1-pentyne conversion and corresponding H/Pd values during in situ PGAA experiments utilizing an unsupported Pd black catalyst. All these experiments were carried out using $4 \mathrm{~cm}^{3} \mathrm{~min}^{-1}$ hydrogen and $1.6 \mathrm{~cm}^{3} \mathrm{~min}^{-1} 1$ pentyne flow. 1-Pentyne was dosed via $\mathrm{N}_{2}$ flow through a saturator. Experiments have not been performed directly after each other and the prehistory of the sample was always different. 


\section{Insights from theory into the Pd-C-H system}

Experimental observations of modifications of the Pd surface in the near-surface region, including the formation of a carbonized surface phase $(\mathrm{Pd}-\mathrm{C}$ phase) or the presence of a metal hydride phase, due to external pressure conditions and total fragmentation of a significant amount of reactant molecules, have been described in the previous section. To understand the formation of both phases, the stability of carbon and hydrogen on the surface and in the subsurface of $\mathrm{Pd}$ was further studied from DFT calculations and first principle thermodynamics.

Carbon binds strongly on the surface of $\operatorname{Pd}(111)$, with an adsorption energy of $-6.9 \mathrm{eV}$ in three-fold hollow sites, but adsorption in the subsurface octahedral site is even more stable by $-0.6 \mathrm{eV}$. The optimal coverage of carbon in this subsurface is $1 / 3 \mathrm{ML}$ and above this value repulsion between the carbon atoms occurs. Absorption of $\mathrm{C}$ in the second interlayer is only slightly less stable and, for a coverage higher than $1 / 3 \mathrm{ML}$, carbon atoms will prefer to be distributed between first and second inter-layers. Similarly, above a coverage of $2 / 3 \mathrm{ML}$, the third interlayer will be populated in the most stable carbon distribution. In this process, a surface carbide is formed with a local formula of $\mathrm{Pd}_{75} \mathrm{C}_{25}$, in reasonable agreement with the experimentally determined concentration [23]. Such a Pd carbide does not exist as a macroscopic bulk phase and is specific to the surface.

The energy of these structures with different amount of subsurface $\mathrm{C}$ cannot be compared directly, and their relative stability is a function of the carbon chemical potential. The surface free energy of the most stable termination, as a function of carbon chemical potential $\mu_{\mathrm{C}}$, is shown on Figure 3 . If $\mu_{\mathrm{C}}$ is very low, the bare surface is the most stable termination. However above a critical value $\left(\mu_{\mathrm{c}} \sim-8.8 \mathrm{eV}\right)$ the termination with a $1 / 3$ $\mathrm{ML}$ coverage of subsurface carbon becomes most stable. For even higher $\mu_{\mathrm{c}}$ values, two layers, and then 3 layers, etc ... will be occupied. The thickness of the Pd-C is hence directly related with the chemical potential of carbon.

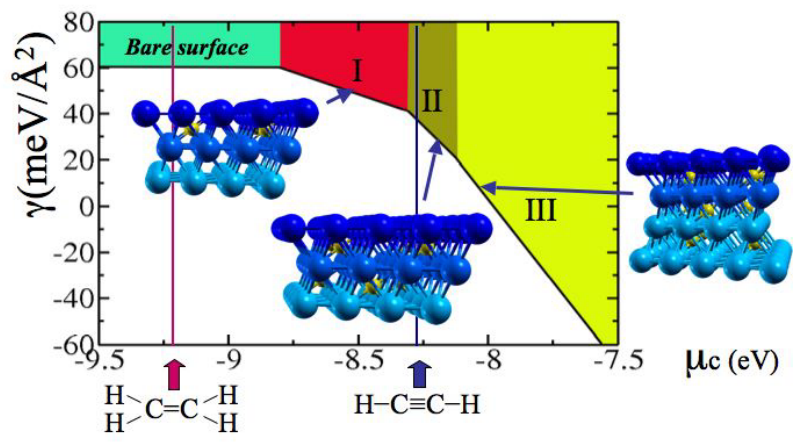

Figure 3: Surface free energy $\gamma\left(\mathrm{meV} / \AA^{2}\right)$ of the most stable $\mathrm{Pd} / \mathrm{C}$ termination as a function of the carbon chemical potential $\mu_{C}$ in eV (the reference for $\mu_{C}$ is the non spin-polarized $C$ atom). The vertical blue and red bars indicate the $\mu_{C}$ value of acetylene and ethylene respectively in the model conditions of hydrogenation of Figure 1.

The effective value of $\mu_{\mathrm{c}}$ under hydrogenation conditions depends on the choice of the unsaturated molecule. For example if the reactant is acetylene the carbon formation reaction is

$$
\mathrm{C}_{2} \mathrm{H}_{2(\mathrm{~g})} \rightleftarrows 2 \mathrm{C}\left({ }^{*}\right)+\mathrm{H}_{2(\mathrm{~g})}
$$

And hence the effective $\mu_{\mathrm{c}}$ can be obtained from the chemical potential of the gas phase molecules, derived from the statistical thermodynamics of the ideal gas:

$$
\mu_{\mathrm{C}}=1 / 2\left(\mu_{\mathrm{C} 2 \mathrm{H} 2}-\mu_{\mathrm{H} 2}\right)
$$

In the conditions of the model reaction shown in Figure $1, \mu_{\mathrm{C}}$ is $-8.25 \mathrm{eV}$ and is in the region of the diagram where a two layer $\mathrm{Pd}-\mathrm{C}$ phase is the most stable termination. Increasing the $\mathrm{C}_{2} \mathrm{H}_{2}$ pressure increases $\mu_{\mathrm{C}}$ and hence favors the formation of the Pd-C phase, while an increased $\mathrm{H}_{2}$ partial pressure or temperature acts in the opposite direction. The calculated thickness of the Pd-C phase is lower than the experimental value. Indeed the extended (111) surface is more difficult to deform and less efficiently accommodates the surface carbide than nanoparticles or a polycrystalline foil. Core level shifts of $\mathrm{Pd}$ in the surface carbide have been calculated and they are in good agreement with the measured values [29].

If the hydrocarbon molecule is ethylene, carbon is more stable which is reflected by a lower $\mu_{\mathrm{C}}$ value $(\sim-9.2 \mathrm{eV}$ in the conditions of Figure 3 ), now in a region of the diagram where the bare $P d$ surface is the most stable termination. The difference in carbon chemical potential hence explains why the $\mathrm{Pd}-\mathrm{C}$ surface phase is formed under acetylene hydrogenation but not under ethylene hydrogenation conditions. The approach has been extended to twelve transitions metal surfaces in the Groups 8 to 11 of the periodic table and to other reactants as a carbon source. The aim was to understand the trends that govern the formation of surface carbide in the conditions of catalytic reactions. $\mathrm{Pd}, \mathrm{Ni}$ and Fe surfaces are very prone to this modification [30].

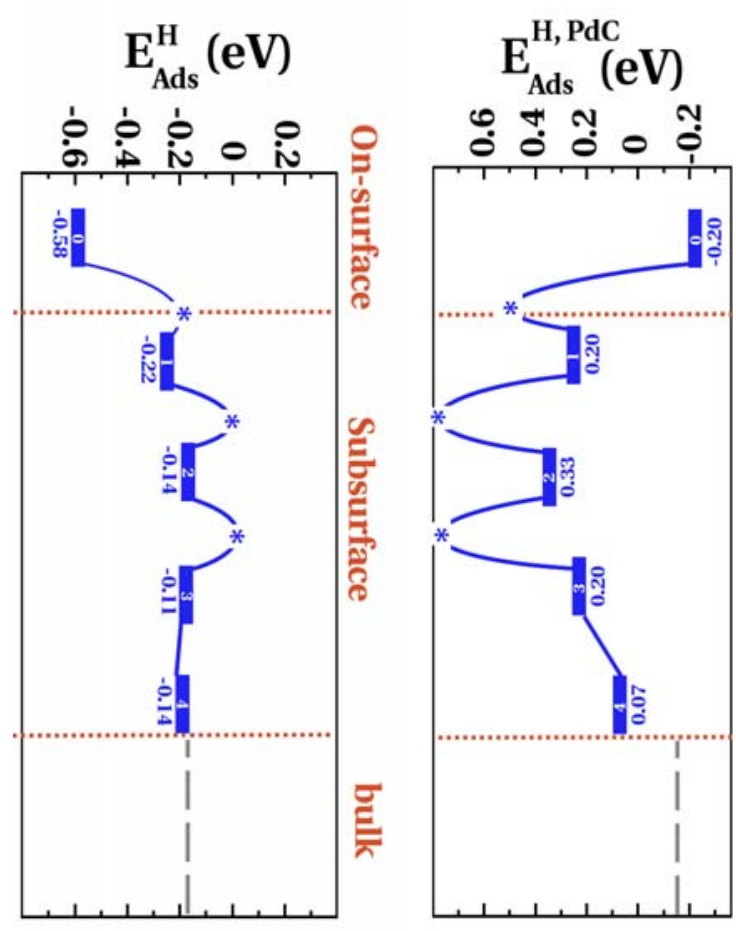

Figure 4: (Right panel) Energy profile for the adsorption and migration of $\mathrm{H}$ towards the bulk for pure $\mathrm{Pd}(111)$. (Left panel) Energy profile for the adsorption and migration of $\mathrm{H}$ towards the bulk in the presence of a 3-layer $\mathrm{Pd}-\mathrm{C}$ phase. Horizontal doted lines are used to differentiate the three different binding zones of $\mathrm{Pd}$, while the vertical dashed lines indicate the hydrogen binding energy on bulk Pd. 
We also addressed hydrogen accumulation in the near surface region from the study of the hydrogen adsorption on the surface and in the first interlayer for a wide coverage range (Fig. 4). For surface adsorption, threefold hollow sites are the most stable ones, as previously reported [31,32], fcc and hcp sites being energetically equivalent. For subsurface absorption, several sites are associated to a similar energy, the $h c p-1$ tetrahedral sites, with a $\mathrm{Pd}$ atom located in the layer below, being the most stable site. The surface adsorption $\left(E_{a d s}=-0.6 \mathrm{eV}\right.$ with respect to $1 / 2 \mathrm{H}_{2}$ in the gas phase) is strongly favored versus subsurface $\left(E_{a d s}=-0.2 \mathrm{eV}\right)$ and bulk absorption in the case of the pure $\mathrm{Pd}(111)$ surface and therefore the surface will be populated until a coverage of 1 before subsurface absorption can happen.

The presence of the $\mathrm{Pd}-\mathrm{C}$ phase strongly weakens hydrogen adsorption. It remains exothermic on the surface, but the adsorption energy is decreased to $-0.2 \mathrm{eV}$, while the penetration of $\mathrm{H}$ in the subsurface within the $\mathrm{Pd}-\mathrm{C}$ phase becomes endothermic by $+0.2 \mathrm{eV}$ for the best $\mathrm{H}$ position. Hence the presence of hydrogen atoms in the subsurface for the $\mathrm{Pd}-\mathrm{C}$ phase is thermodynamically disfavored. Over clean Pd, the overall penetration barrier from surface to bulk is $0.6 \mathrm{eV}$, whereas the extraction barrier is $0.1 \mathrm{eV}$. On the $\mathrm{Pd}-\mathrm{C}$ phase, the barrier is only moderately higher for the penetration, $0.9 \mathrm{eV}$, but considerably increased for the extraction, $0.8 \mathrm{eV}$. Due to the weaker $\mathrm{H}$ absorption, the increased extraction barrier for $\mathrm{H}$ and the exclusion zone in the subsurface the surface coverage will be low that strongly facilitates partial hydrogenation.

The thin Pd-C phase also has an important influence on the adsorption of the unsaturated hydrocarbon. In a recent paper, the group of Nørskov addressed the role of surface modifications on the hydrogenation of acetylene [19]. They showed that the heat of adsorption of ethylene and acetylene were the main factors controlling selectivity. In this way, a weakening of ethylene adsorption will lead to a selectivity increase, while a weakening of acetylene bonding will eventually lead to a decrease in the rate of acetylene hydrogenation. Interestingly enough, they found that the presence of subsurface $\mathrm{C}$ in $\mathrm{Pd}$ weakens the adsorption of the double bond molecule. The olefin will be faster desorbed, hence preventing its further hydrogenation which is a key aspect for the selectivity. Lopez and co-workers calculated the hydrogenation reaction barriers and showed that the surface carbide impacts on the hydrogenation selectivity also by preferential formation of ethene versus ethylidene [15]. In this work it was also reported that the stability of the $\mathrm{Pd}-\mathrm{C}$ layer depends on the concentration of $\mathrm{H}_{2}$ and $\mathrm{CO}$. Thus, it is not the best handle to control selectivity.

In summary, DFT calculations confirm the formation of a Pd-C surface phase under selective hydrogenation conditions and indicate that the low exothermic chemisorption energy of $\mathrm{H}$, the endothermic adsorption in subsurface position as well as the increased energy barrier for $\mathrm{H}$ penetration through the subsurface are critical ingredients to achieve low surface $\mathrm{H}$ coverages resulting in a preferential partial hydrogenation.

\section{Pd-Ga intermetallic compounds as hydrogenation catalysts}

The role of subsurface carbon on selectivity has been highlighted in the two first sections of this review, and the question arises, whether it is possible to find a replacement for the carbon acting in the same way on the catalytic properties of $\mathrm{Pd}$, but which can be reproducibly prepared in a more controlled manner and which exhibit a wider range of stability. The replacement should possess strong covalent bonds to the palladium atoms - excluding conventional alloys - to form a stable compound, which can be easier investigated. Furthermore, it should be effective in decoupling the hydrogenation rate from the bulk hydrogen content (if forming a hydride at all) to enable high selectivity in the semi-hydrogenation of alkynes. The latter should preferably not be dependent on a complex fragmentation mechanism happening in situ, but represent the intrinsic structural and electronic properties of the Pd- $X$ material. Besides these two requirements, the compound must be able to activate hydrogen and adsorb the hydrocarbon, i.e. there must be free electronic states in the vicinity of the Fermi level.

A class of compounds, which can combine these requirements, are intermetallic compounds [33]. These differ from alloys by being single phase materials. In addition, they possess an at least partially ordered crystal structure, which differs from the crystal structure(s) of the constituent elements [34]. The different crystal structure results in a strongly altered electronic structure, which is influenced by the often covalent interactions between the atoms $[35,36]$. Since the electronic structure is responsible for the adsorption properties, the catalytic properties of intermetallic compounds can be very different of those of the elements forming the compound [37]. In contrast to alloys, the composition cannot be chosen arbitrarily and the observed catalytic properties cannot be explained by a linear combination of the properties of the constituent elements.
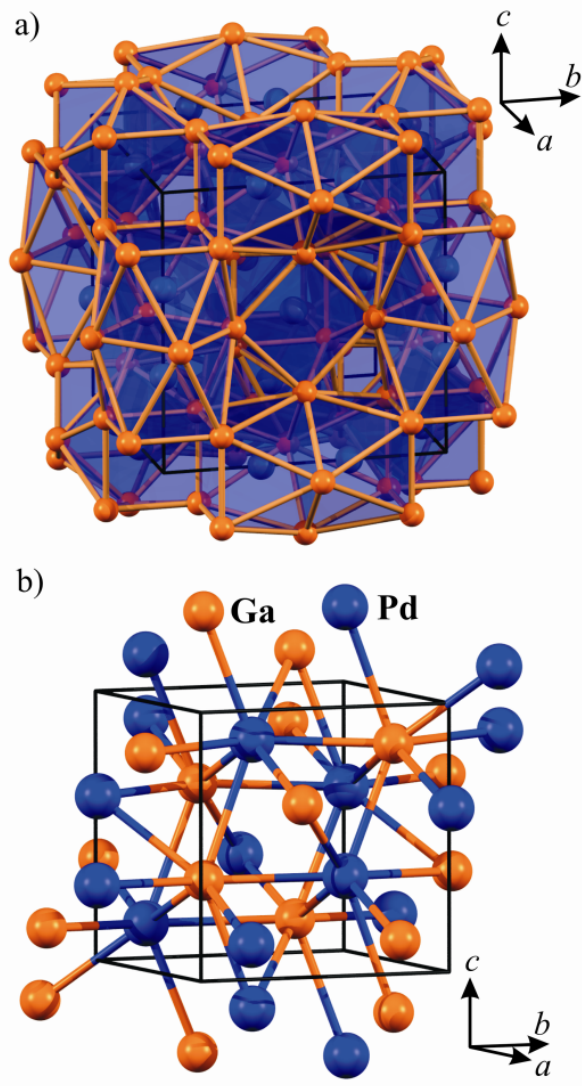

Figure 5: The crystal structures of the intermetallic compounds $\mathrm{Pd}_{3} \mathrm{Ga}_{7}$ (a) and $\mathrm{PdGa}$ (b). While in $\mathrm{Pd}_{3} \mathrm{Ga}_{7}$ the $\mathrm{Pd}$ atoms are grouped in pairs, only single $\mathrm{Pd}$ atoms are present in PdGa. In both structures the Pd units are completely isolated from each other by $\mathrm{Ga}$. 
One possible replacement for the subsurface carbon is gallium, which forms intermetallic compounds with palladium in different ratios. Examples for Pd-Ga intermetallic compounds are $\mathrm{Pd}_{3} \mathrm{Ga}_{7}$ and $\mathrm{PdGa}$. Both compounds realize crystal structures in which the $\mathrm{Pd}$ atoms possess only one or none $\mathrm{Pd}$ atom, respectively, in the first coordination sphere, thus following the active-site isolation concept. $\mathrm{Pd}_{3} \mathrm{Ga}_{7}$ crystallises in the $\mathrm{Ir}_{3} \mathrm{Ge}_{7}$ type of structure $(I m \xi m, a=8.7716 \AA[38]$, while $\mathrm{PdGa}$ is a representative of the FeSi type of structure $\left(P 2{ }_{1} 3, a=4.890 \AA\right.$, [39]) (Fig. 5).

Using a metallurgical synthesis starting from the elements as sources for $\mathrm{Ga}$ and $\mathrm{Pd}$, bulk model catalyst of $\mathrm{Pd}-\mathrm{Ga}$ intermetallic compounds can be obtained. The unconventional state of the catalysts, i.e. the absence of any support, enables in depth characterization of the compounds before and during the reaction, which allows to detect even small changes to the material under in situ conditions. Using unsupported material also facilitates a knowledge-based development of the catalyst because the observed catalytic properties can directly and solely be assigned to the given crystal and electronic structure of the compound - if the compound is stable under in situ conditions. The crucial stability tests of $\mathrm{Pd}_{3} \mathrm{Ga}_{7}$ and $\mathrm{PdGa}$ were performed in different atmospheres $\left(\mathrm{H}_{2}, \mathrm{O}_{2}\right.$ and acetylene hydrogenation mixture) and investigated by several in situ techniques.

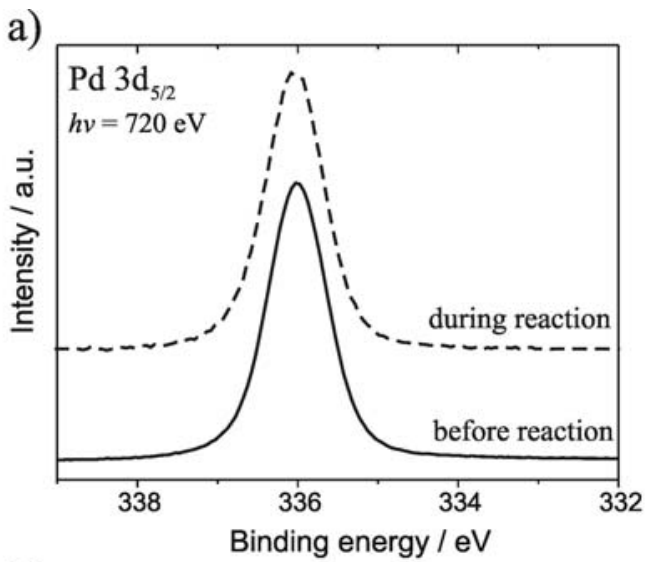

b)

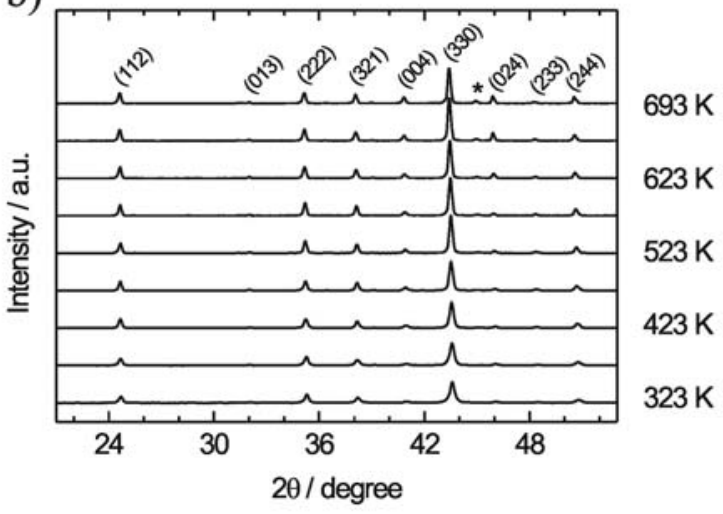

Figure 6: a) Comparison of UHV and high pressure in situ XPS measurements $\left(P d 3 d_{5 / 2}\right)$ of $P d G a$. No significant changes between the two measurements are observed. b) X-ray diffraction of $\mathrm{Pd}_{3} \mathrm{Ga}_{7}$ in $50 \% \mathrm{H}_{2}$ in helium, proving the absence of hydride formation. At high temperatures, small amounts of $\mathrm{PdGa}$ are formed.

Neither bulk (XRD, EXAFS, PGAA, DTA/TG) nor surface sensitive methods (XPS, FTIR) could detect any changes of the material under reactive atmospheres, even above the high reaction temperature of $200{ }^{\circ} \mathrm{C}$, which was chosen for the catalytic tests (Fig. 6) [ 40,41$]$. High-pressure in situ XPS measurements excluded segregation under reaction conditions. Only a narrow single $\mathrm{Pd} 3 \mathrm{~d}_{5 / 2}$ symmetric signal is detected for $\mathrm{PdGa}$ with a binding energy of $336.0 \mathrm{eV}$ which is close to the binding energy observed for the subsurface Pd-C (335.5 eV). For $\mathrm{Pd}_{3} \mathrm{Ga}_{7}$ the shift is more pronounced and the $\mathrm{Pd} 3 \mathrm{~d}_{5 / 2}$ signal is observed at $336.5 \mathrm{eV}$ [42]. No further shift of the Pd 3d core level or any additional signals were detected under in situ conditions for both compounds.

Some intermetallic compounds are known to form hydrides upon which they change their electronic and their crystal structure [43]. The formation of hydrides must be excluded to allow the abovementioned correlation between crystal and electronic structure on the one hand and the observed catalytic properties on the other hand. Temperature dependent XRD and PGAA investigations in hydrogen as well as in reactive atmosphere excluded the formation of hydrides very clearly under conditions for which hydride formation of pure Pd is detected [41]. Also, hydride incorporation in the near surface region would have resulted in additional or shifted signals in the in situ XPS measurements, which was not the case. To conclude, our in situ characterization confirmed the high stability of the bulk as well as the surface and the presence of only site-isolated $\mathrm{Pd}$ atoms on the surface. In addition, a strong modification of the electronic structure was observed, which did not change under reaction conditions.

An obvious advantage of PdGa over the in situ formed Pd-C phase is the stability of the selective phase in a wide range of experimental conditions (e.g. at high hydrogen/alkyne pressure ratios) as well as the possibility to prepare and characterize the $\mathrm{Pd}-\mathrm{Ga}$ intermetallic compounds in an intended way prior to the catalytic reaction due to their in situ stability. In this case, the subsurface properties are completely rendered by the bulk structure of the catalyst allowing a much higher level of control of the synthetic chemist on the changes usually induced by the subsurface chemistry and, thus, of the related catalytic properties.

The catalytic properties of $\mathrm{Pd}_{3} \mathrm{Ga}_{7}$ and $\mathrm{PdGa}$ were tested in the semi-hydrogenation of acetylene in a large excess of ethylene $\left(0.5 \% \mathrm{C}_{2} \mathrm{H}_{2}, 5 \% \mathrm{H}_{2}, 50 \% \mathrm{C}_{2} \mathrm{H}_{4}\right.$ in $\left.\mathrm{He}\right)$ at $200^{\circ} \mathrm{C}$ and atmospheric pressure [44]. To exclude influences of the support the compounds were investigated in an unsupported state solely diluted with inactive and inert $B N$ to improve the flow characteristics. As expected, the catalytic properties are excellent (Fig. 7a). Besides a very high selectivity, the compounds also possess a high stability with time on stream. Both observations can be attributed to the small active sites as well as the modified electronic structure. These effects do not only prevent the total hydrogenation to ethane but also avoid side-reactions, which can take place on large surface ensembles and result in coke formation and deactivation of the catalyst [16]. The two-fold beneficial effect of the modified structural and electronic properties can clearly be seen by comparison of the catalytic properties of the intermetallic compounds and elemental palladium in Figure 7 . Increasing the activity by top-down methods, e.g. milling or etching, results in structural defects, decreasing the selectivity of the compounds $[45,46]$. To avoid the structural changes and to prove the applicability of the concept also to materials with high specific surface areas, we developed a synthesis route to unsupported nanoparticulate intermetallic $\mathrm{Ga}$ Pd compounds [47]. Figure 7 comprises catalytic data of such a 
highly active nanostructured catalyst, showing the possibility to transfer the excellent catalytic properties also to these highly active materials.

The situation becomes different when the hydrogenation reaction is carried out in the liquid phase in a batch reactor. As model reaction phenylacetylene was hydrogenated to styrene (and ethylbenzene due to total hydrogenation) at 4 bar and $40{ }^{\circ} \mathrm{C}$ using octane as inert solvent. When unsupported powdered $\mathrm{Pd}_{2} \mathrm{Ga}, \mathrm{PdGa}$ and elemental $\mathrm{Pd}$ are compared (Fig. 8) no significant differences in the selectivity to styrene $(88.5-90.5 \%$ at $100 \%$ conversion) are visible. Lindlar's catalyst provides a higher selectivity of $95.5 \%$ at $100 \%$ conversion. The high selectivity of this widely-utilized $\mathrm{Pd}-\mathrm{Pb} / \mathrm{CaCO}_{3}$ catalyst [48] is deduced not to be related to alloying or intermetallic compound formation [49]. Partial poisoning of $\mathrm{Pd}$ with $\mathrm{Pb}$ is ascribed to hinder hydride formation and weakens the olefin adsorption [50] similar as described above for $\mathrm{C}$ and $\mathrm{Ag}$ promoters. Furthermore, quinoline tend to isolate $\mathrm{Pd}$ sites thus minimizing oligomerization. The intermetallic compounds can undergo an oxidative passivation at the outermost surface into oxidized $\mathrm{Ga}$ and metallic Pd. The reducing conditions in the liquid phase are not strong enough to re-form the intermetallic compound at the surface, while the selective sites in Lindlar's catalyst are formed in situ [51]. Through the high oxophilicity of $\mathrm{Ga}$ at the surface a reductive pretreatment and reaction procedure in absence of any traces of oxygen and water is necessary to get a stable intermetallic surface under these conditions.

a)
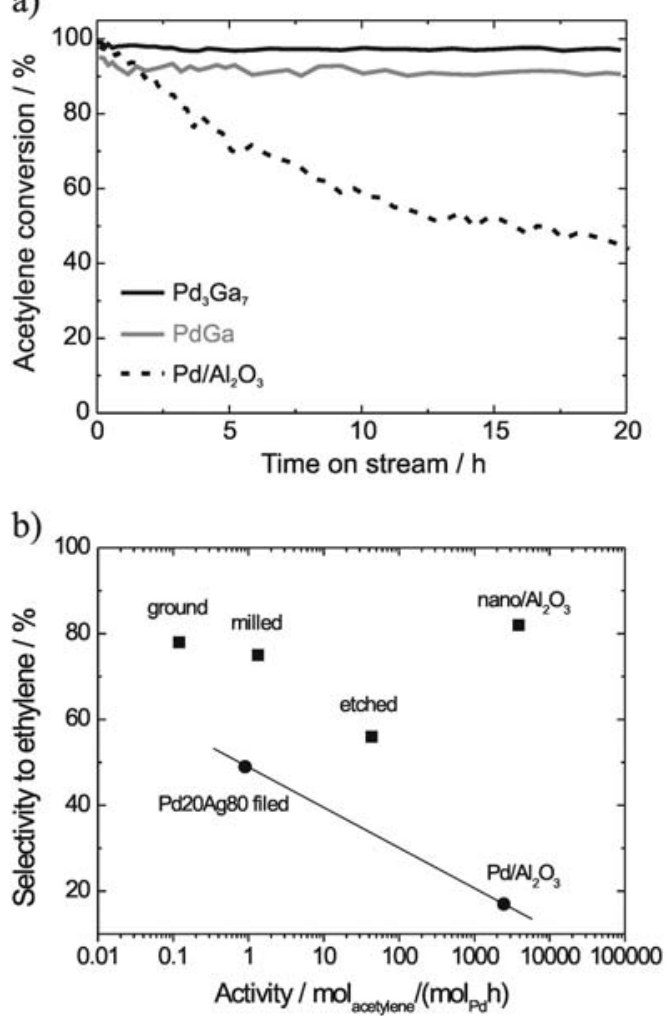

Figure 7: a) Stability with time on stream of the intermetallic compounds $\mathrm{Pd}_{3} \mathrm{Ga}_{7}$ and $\mathrm{PdGa}$ in comparison with a commercial $\mathrm{Pd} / \mathrm{Al}_{2} \mathrm{O}_{3}$. b) Selectivity vs. activity of $\mathrm{PdGa}(\boldsymbol{\square})$ after different treatments. The black line indicates the transition of $\mathrm{Pd} / \mathrm{Al}_{2} \mathrm{O}_{3}$ to an unsupported $\mathrm{Pd}-\mathrm{Ag}$ alloy. Remarkable is the high activity and selectivity of nanoparticulate $\mathrm{PdGa}$ supported on $\mathrm{Al}_{2} \mathrm{O}_{3}$ after synthesis compared with $\mathrm{Pd} / \mathrm{Al}_{2} \mathrm{O}_{3}$

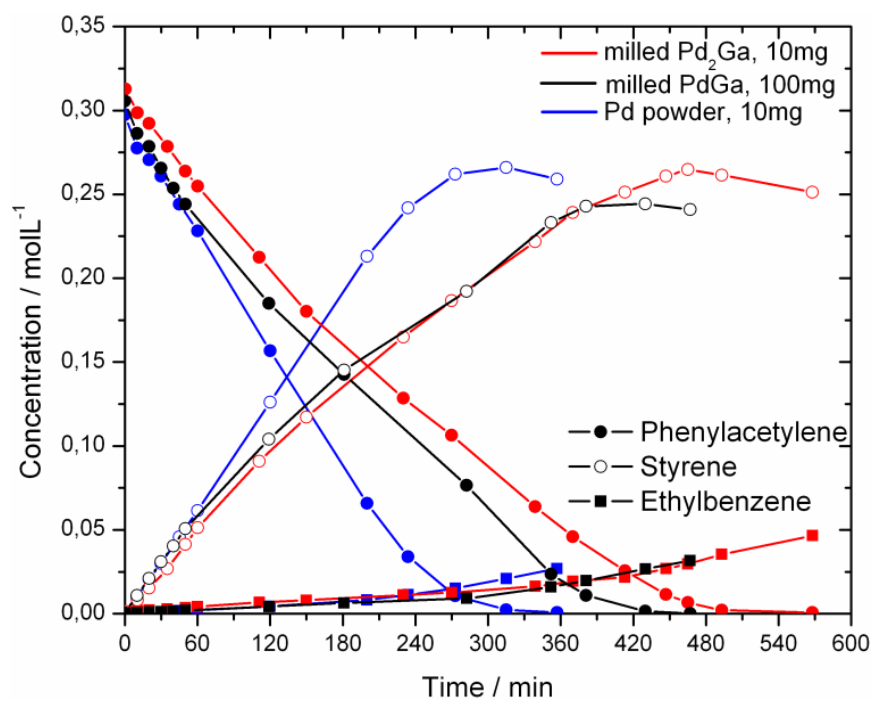

Figure 8: Concentration profile of phenylacetylene and its products during liquid phase hydrogenation in octane at 4 bar and $40^{\circ} \mathrm{C}$. Observed selectivities are very similar for $\mathrm{Pd}_{2} \mathrm{Ga}, \mathrm{PdGa}$ and elemental $\mathrm{Pd}$ while the specific activity increases with decreasing $\mathrm{Ga}$ content. These catalytic properties are likely not to be characteristic for a perfect intermetallic surface, but represent a decomposed surface with a $\mathrm{Pd} / \mathrm{Ga}$-oxide layer.

In summary, Pd-Ga intermetallic compounds were introduced as materials with catalytic characteristics analogous to the selective $\mathrm{Pd}-\mathrm{C}$ surface phase. In a simple picture, they can be seen as stable bulk analogues of $\mathrm{Pd}-\mathrm{C}$ providing active site isolation and preventing the formation of bulk-hydrides under hydrogenation conditions due to their modified electronic structures. The nanostructured synthesis combines the excellent selectivity and stability with the desired high activity.

\section{Single Crystal Surfaces of PdGa}

Surface science studies of single crystal surfaces can help to relate the structure and composition of surfaces with the reaction rates and selectivities of catalytic reactions [52]. In particular the combination of both single-crystal model catalysts and real catalytic systems using UHV methods and high-pressure kinetic techniques provides valuable insights [ 53,54$]$. As described in detail in the other sections of this review, a large variety of "high-pressure" techniques has already been applied to investigate intermetallic $\mathrm{Pd}-\mathrm{Ga}$ compounds. These techniques give a good insight into the overall catalytic properties [40,44], but cannot yield a detailed comprehension of the local surface atomic arrangement, the surface electronic structure and the adsorption sites, which is crucial to understand the atomistic catalytic reaction mechanisms. To approach these questions for the intermetallic compound $\mathrm{PdGa}$, structural characterization studies of the (111) and (III) surfaces were performed by means of different UHV techniques. Low energy electron diffraction (LEED)-I(V), scanning tunneling microscopy (STM), XPS, X-ray photoelectron diffraction (XPD), ultra violet photoelectron spectroscopy (UPS,) and thermal desorption spectroscopy (TDS) have been been applied together with ab-initio thermodynamics calculations $[55,56]$. UPS results have been reported for PdGa(110) [57].

XPD patterns of $\mathrm{PdGa}(111)$ and $\mathrm{PdGa}$ (III) surfaces clearly reveal the absence of surface segregation upon sputter and 
annealing cycles. Segregation of individual species to the surface has been observed on other multi-metal hydrogenation catalysts to affect the selectivity pattern and complicate the analysis of the active and selective state of the catalyst [58]. Despite the absence of segregation, more experimental effort was necessary to unambiguously determine the surface termination of the crystal under investigation. The surface of PdGa was observed to be chiral as this material is of the $P 2{ }_{1} 3$ space group. As a consequence of the crystal structure, the XPD patterns of the (111) and the (III) surfaces show non-superimposable mirror images of each other [55]. Four unreconstructed (1x1) terminations are possible for each of the (111) and (III) surfaces [55]. The enantiomorphic form of PdGa single crystals and the terminations after annealing at $870 \mathrm{~K}$ were unambiguously determined by means of LEED-I(V) and also visualized by highresolution STM. In Figure 9, an atomically resolved STM image of two terraces at the $\mathrm{PdGa}(111)$ surface with an overlaid bulk truncated structure model is shown. Due to a shift of the trimeric atoms in the structure from one terrace to the next one, a match between the STM image and the structure model is only possible for form B, but not for form A. All of the atomically flat terraces of various widths are separated by one unique step height. The latter is equal to $284 \mathrm{pm}$ as indicated in the height histogram in Fig. 9, which corresponds very well to one third of the XRD lattice parameter along the [111] direction [30,50]. Additionally, the inplane periodicity of the site isolation of the trimers on the $\mathrm{PdGa}: \mathrm{B}(111)$ surface being $0.692 \mathrm{~nm}$, whereas on the $\mathrm{PdGa} B$ (III) surface single atoms are separated by the same distance, is clearly discernible.

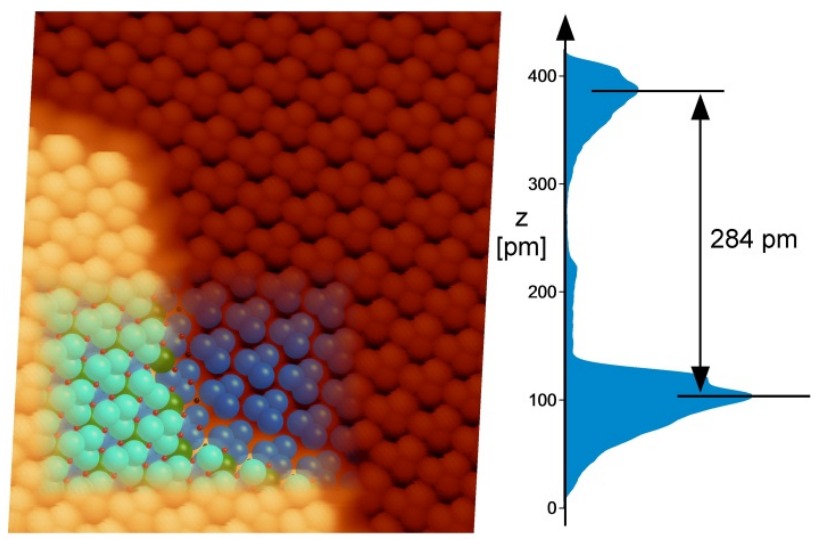

Figure 9: Atomically resolved STM images of two PdGa(111) terraces with overlaid structure model of form $B$, scan size: $6.9 \times 7.8 \mathrm{~nm}^{2}$. The height histogram of this STM image to the right reveals the bulk periodicity of equivalent atomic layers of $284 \mathrm{pm}$ along the [111] direction.

In principle CO TDS should also be able to discriminate between the different surface terminations of PdGa due to their different near surface composition. Furthermore, the adsorption properties of the intermetallic surface are directly related to the catalytic properties and can be studied using $\mathrm{CO}$ as a probe molecule. CO adsorption was carried out on the PdGa:B(III) surface and additionally on $\mathrm{Pd}(111)$ for comparison (Fig. 10).

Intensity calibration and integration of the $\gamma$ and $\beta$ states yields one $\mathrm{CO}$ molecule per PdGa:B(III) unit cell $\left(0.4153 \mathrm{~nm}^{2}\right)$, which is $2.4 \mathrm{CO}$ molecules per $\mathrm{nm}^{2}$ as compared to $11.5 \mathrm{CO}$ molecules per $\mathrm{nm}^{2}$ for a full coverage of $\mathrm{Pd}(111)$. The first order desorption behavior of the $y$ state in an adsorption series (not shown here) and the results of LEED-I(V) and STM lead to the assumption of $\mathrm{CO}$ adsorption on the isolated $\mathrm{Pd}_{1}$ ensemble. The very low $\mathrm{CO}$ desorption temperature compared to $\mathrm{Pd}(111)$ reveals a strong electronic perturbation due to partial covalent intermetallic Pd-Ga bonding [55].

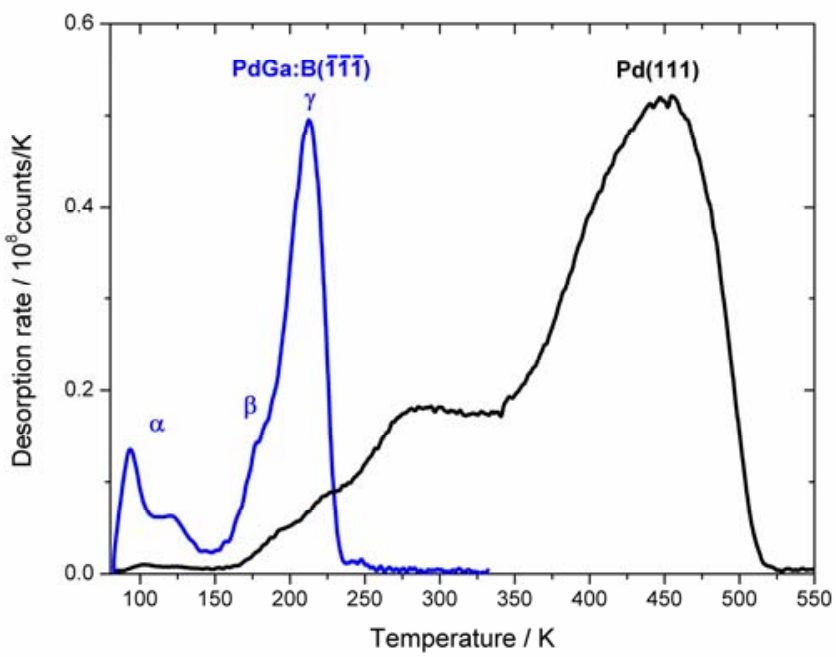

Figure 10: Thermal desorption spectra after adsorption of $\mathrm{CO}$ at $85 \mathrm{~K}$ on $\mathrm{PdGa}: \mathrm{B}$ (111) annealed at $870 \mathrm{~K}$ (heating rate $1.5 \mathrm{~K} / \mathrm{s}$ ). Additionally $\mathrm{CO}$ adsorption was carried out on $\mathrm{Pd}(111)$ for comparison (heating rate $1.4 \mathrm{~K} / \mathrm{s}$, adsorption temperature $85 \mathrm{~K})$. The spectra for $\mathrm{Pd}(111)$ and $\mathrm{PdGa}: \mathrm{B}(111)$ annealed at $870 \mathrm{~K}$ depicts the saturation coverage at 27 and $50 \mathrm{~L}$, respectively.

In summary, it was shown that well-defined terraced surface terminations on the PdGa single crystals can be comprehensively characterized by the applied UHV methods. Such ordered surfaces are ideal candidates to study the catalytic activity of welldefined site-isolated configurations depending on the surface orientation and termination. Additionally, the chirality of the surfaces opens possibilities for enantio-selective reactions on $\mathrm{PdGa}$. In agreement with the concepts of site isolation and stability through covalent bonding, no surface segregation was found on the present crystal and the termination of isolated $\mathrm{Pd}_{1}$ atoms shows strongly altered adsorption properties compared to monometallic Pd surfaces.

\section{Thin film models of Pd-X $(X=G a, Z n, S i)$}

In a previous section, $\mathrm{Pd}-\mathrm{Ga}$ intermetallic compounds were introduced as a novel class of selective hydrogenation catalysts and many fundamental insights were obtained on bulk samples prepared by metallurgical methods and single crystal studies. Unfortunately, these model catalysts suffer from a low specific surface area due to their high temperature preparation. To explore alternative preparation methods, we focus in this section on the solid state reactivity of $\mathrm{Pd}$ nanoparticles in contact with different $X$-oxides to study the formation of $\mathrm{Pd}-X$ intermetallic compounds $(X=\mathrm{Si}, \mathrm{Zn}, \mathrm{Ga})$ under reducing conditions by highresolution electron microscopy (HRTEM).

The need for adequate electron transparent specimens suited for HRTEM has led to the development of a special type of thin film model catalysts consisting of regular metal particles grown on $\mathrm{NaCl}(001)$ cleavage faces and supported by a thin film of the respective oxide. The epitaxially grown nanoparticles provide a well-defined initial state of the Pd/oxide system, and the following 
structural and morphological changes can be documented as a function of the respective treatments. Epitaxially grown metal films are very well suited for lattice imaging by HRTEM, especially in the profile-imaging mode which is restricted to particular lowindex orientations of the particles and of their surfaces [59]. With help of HRTEM and selected area electron diffraction (SAED), structural details of small metal, oxide or intermetallic compound particles can be revealed at an atomic scale, providing direct evidence for the metal-support interactions important for the synthesis of $\mathrm{Pd}-X$ intermetallic compounds. A representative image of the initial, untreated state of such an oxide-supported $\mathrm{Pd}$ thin film model catalyst is shown in the upper panel of Figure 11, denoting an overview TEM image of a $\mathrm{Pd} / \mathrm{ZnO} / \mathrm{SiO}_{2}$ catalyst (a), along with its SAED pattern, exclusively showing $\mathrm{Pd}$ metal reflections due to a [001] zone axis (b). $\mathrm{ZnO}$ is amorphous and does not contribute to the SAED pattern.

As a general phenomenon, reductive activation of a series of oxide-supported $\mathrm{Pd}$ catalysts in $\mathrm{H}_{2}$ will induce the formation of $\mathrm{Pd}-X$ intermetallic compounds as a function of the reducibility of the respective $X$-oxide [60], which has also been observed for several Pd- $X$ systems by HRTEM using the above mentioned thin film method ( $X=\mathrm{Zn}$ [61], Ga [62], In [63], Sn, Ge, Si [64], Al [65]). The formation of the respective $\mathrm{Pd}-X$ intermetallic compounds was identified as a subsequent process to formation of $\mathrm{Pd}-\mathrm{H}$ phases such as $\beta$-palladiumhydride, and a strong dependence on the respective support material and activation conditions was observed. Before discussing the reactivity of the $\mathrm{Pd}-\mathrm{Ga}_{2} \mathrm{O}_{3}$ system towards formation of intermetallic compounds, we may pin down the two extreme cases of non-reducible and reducible oxide supports. $\mathrm{ZnO}$ serves an example for the latter case, while hard to reduce oxides are represented by $\mathrm{SiO}_{2}$.

Reduction of the $\mathrm{Pd}-\mathrm{SiO}_{2}$ thin film system at low reduction temperatures $(\sim 523 \mathrm{~K})$ and subsequent transfer into the vacuum of the microscope leads to complete amorphization of the $\mathrm{Pd}$ particles, which is ascribed to the (intermediate) formation of a $\mathrm{Pd}-\mathrm{H}$ phase probably during cooling of the reduced sample in either clean $\mathrm{H}_{2}$ or a hydrogenation reaction mixture (e.g. $\mathrm{CO}_{2}: \mathrm{H}_{2}$ $=1: 3$ ) [64]. Figure $8 \mathrm{c}$ and $d$ show the corresponding TEM image and the amorphous SAED pattern, respectively. At much higher temperatures $(673 \mathrm{~K})$ we observed formation of $\mathrm{Pd}-\mathrm{Si}$ phases, such as $\mathrm{Pd}_{2} \mathrm{Si}$ [64], which do not form hydrides and preserve their crystal structure. We may conclude that the formation of $\mathrm{Pd}-X$ intermetallic compounds can effectively suppress the ability of a $\mathrm{Pd}$-based catalytic material to form bulk-hydrides in a range of temperature and $\mathrm{H}_{2}$ partial pressure, where $\mathrm{Pd}-\mathrm{H}$ formation is observed for monometallic Pd.

In contrast, highly ordered particles of the intermetallic compound $\mathrm{PdZn}$ are formed upon $\mathrm{H}_{2}$ reduction of $\mathrm{Pd}$ particles embedded in a $\mathrm{ZnO}$ film already at $473 \mathrm{~K}$. The $\mathrm{PdZn}$ particles were observed to be thermally and structurally highly stable upon further heating in $\mathrm{H}_{2}$ between 473 and $873 \mathrm{~K}$. The lower panel of Figure 11 shows the overview TEM image (e), its SAED pattern (f) and a high-resolution TEM image of a single PdZn particle in [011] zone axis orientation (g) after reduction at $523 \mathrm{~K}$. Even above $873 \mathrm{~K}$ only partial decomposition of the intermetallic compound $\mathrm{PdZn}$ was observed, accompanied by strong interaction with the $\mathrm{SiO}_{2}$ support and resulting in the formation of $\mathrm{Pd}$-rich silicides. This broad stability range is clearly due to the higher stability of the $1: 1 \mathrm{PdZn}$ intermetallic compound compared to $\beta$-palladiumhydride. The higher reactivity of the $\mathrm{Pd}-\mathrm{ZnO}$ system compared to $\mathrm{Pd}-\mathrm{SiO}_{2}$ can be attributed to the stronger interaction of $\mathrm{Pd}$ with the $\mathrm{ZnO}$ support due to its higher reducibility. These results indicate that $\mathrm{Pd}-X$ intermetallic compounds are accessible in form of nanoparticles at relatively low temperatures using oxides as the source for $X$, if the reduction of this oxide is favourable at such conditions. In case of the Pd-Zn system, the importance of this concept for the catalytic properties of $\mathrm{Pd} / \mathrm{ZnO}$ catalysts has been highlighted for methanol steam reforming and methanol synthesis $[66,67]$.
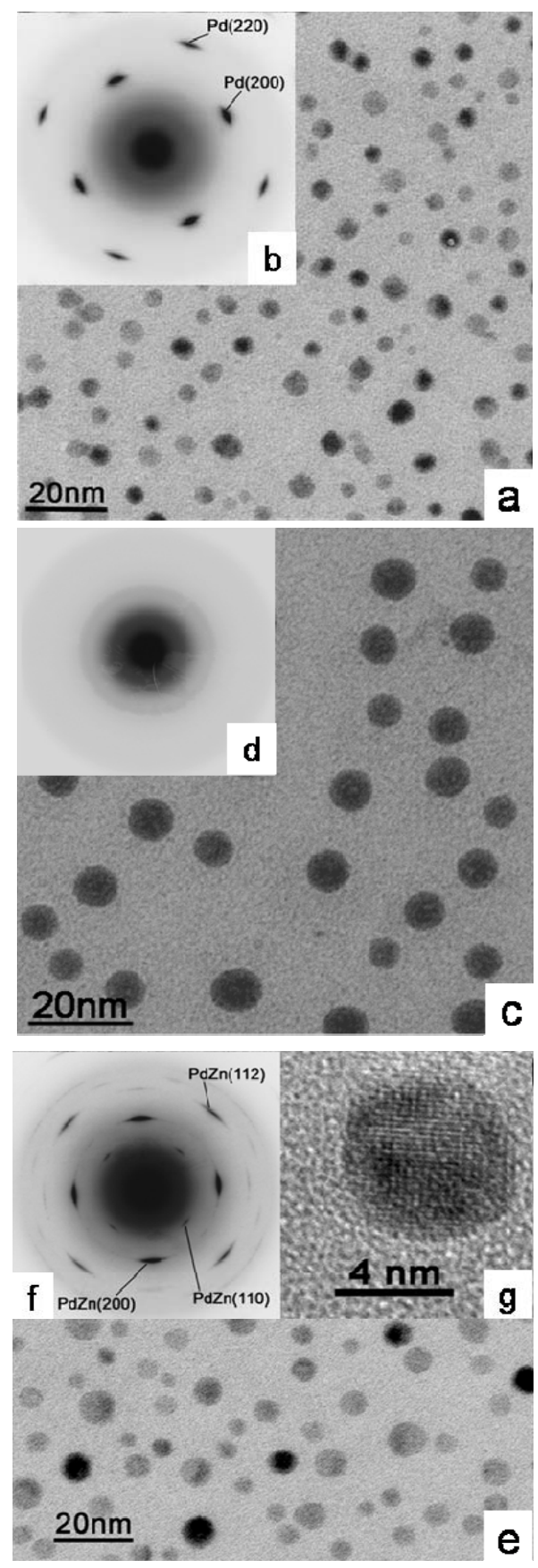

Figure 11: Overview TEM images of the initial, untreated $\mathrm{Pd} / \mathrm{ZnO} / \mathrm{SiO}_{2}$ catalyst (a), a $\mathrm{Pd} / \mathrm{SiO}_{2}$ catalyst reduced in $\mathrm{H}_{2}$ at $523 \mathrm{~K}$ (c) and a $\mathrm{Pd} / \mathrm{ZnO} / \mathrm{SiO}_{2}$ catalyst reduced at $523 \mathrm{~K}$ in $\mathrm{H}_{2}(\mathrm{e})$. The corresponding SAED patterns are shown as insets ( $b, d$ and $f$ ). A high-resolution TEM image of a single $\mathrm{PdZn}$ particle in [011] zone axis is shown in $(\mathrm{g})[61,64]$ 
Finally, the $\mathrm{Pd}-\mathrm{Ga}$ intermetallic catalyst system was investigated by means of the corresponding $\mathrm{Pd}-\mathrm{Ga}_{2} \mathrm{O}_{3}$ thin film model system. In agreement with literature reports [66], the embedded $\mathrm{Pd}$ particles in $\mathrm{Ga}_{2} \mathrm{O}_{3}$ could indeed be transformed by $\mathrm{H}_{2}$ reduction at $523 \mathrm{~K}$ into a $\mathrm{Pd}-\mathrm{Ga}$ intermetallic compound. This newly formed phase could be identified by SAED as $\mathrm{Pd}_{5} \mathrm{Ga}_{2}$ (Fig. 12) confirming the general accessibility of nanoparticulate $\mathrm{Pd}-\mathrm{Ga}$ intermetallic compound catalysts by reduction at moderate temperatures using $\mathrm{Pd}$ and $\mathrm{Ga}_{2} \mathrm{O}_{3}$ as reactants. Hydride formation, as observed on $\mathrm{Pd}-\mathrm{Si}$ samples, was again not detected. It has to be noted, however, that in contrast to the $\mathrm{PdZn} / \mathrm{ZnO}$ system, the resulting $\mathrm{Pd}_{5} \mathrm{Ga}_{2} / \mathrm{Ga}_{2} \mathrm{O}_{3}$ thin film model catalysts are rather prone to sintering starting at a temperature of $673 \mathrm{~K}$ and that significant amounts of unreacted Pd were observed by SAED after reduction (Fig. 12b), which are, however, likely be present only in the cores of the particles while a shell of the intermetallic compound was formed at the metal-oxide interface.

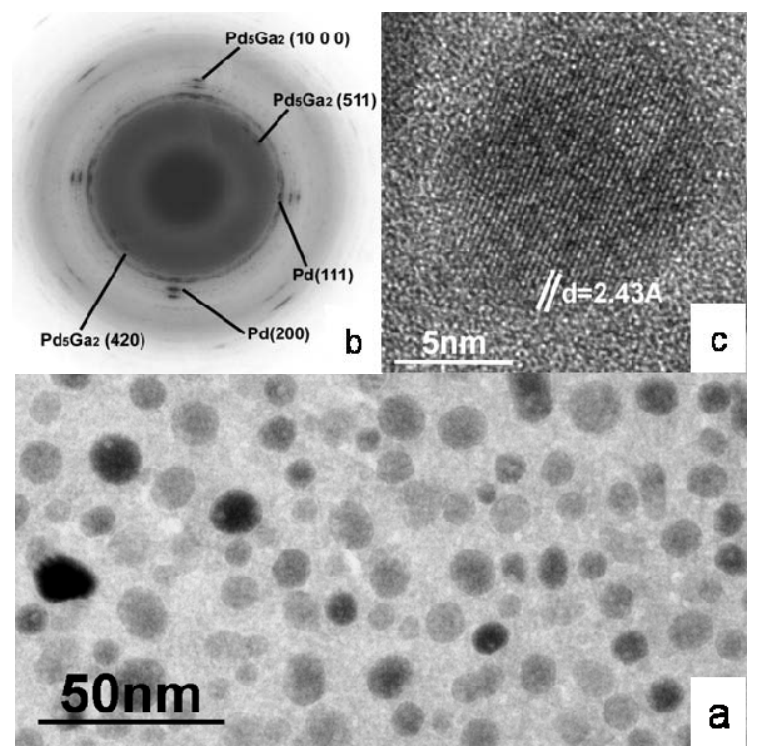

Figure 12: Overview TEM image of the $\mathrm{Pd} / \mathrm{Ga}_{2} \mathrm{O}_{3}$ thin film catalyst after reduction at $673 \mathrm{~K}$ in $\mathrm{H}_{2}$ (a). The corresponding SAED pattern and a HRTEM image of a single $\mathrm{Pd}_{5} \mathrm{Ga}_{2}$ particle are shown in (b) and (c), respectively [65]

In summary, it was shown by means of model systems that the reducibility of $\mathrm{Ga}_{2} \mathrm{O}_{3}$ is sufficient to produce well-ordered $\mathrm{Pd}$ $\mathrm{Ga}$ intermetallic compounds from nano-structured $\mathrm{Pd} / \mathrm{Ga}_{2} \mathrm{O}_{3}$ samples. This reactivity may lead to a feasible preparation route for high performance hydrogenation catalysts based on $\mathrm{Pd}-\mathrm{Ga}$ intermetallics.

\section{Intermetallic Pd-Ga powder catalysts}

As discussed in previous sections, $\mathrm{Pd}-\mathrm{Ga}$ intermetallic compound catalysts exhibit great potential in selective hydrogenation reactions. Employment of these systems in technical applications requires high performance catalysts in form of small particles on an inert, high surface area support. Hence, in the last section we focus on $\mathrm{Pd}$ nanoparticles supported on technological oxide powder materials, their preparation and chemisorption properties.

Several top down approaches for the preparation of $\mathrm{PdGa}$ intermetallic compound catalysts by milling and etching of the compounds have been developed to enlarge the surface area of the unsupported systems described above $[45,46]$. Since the increase in surface area always goes hand in hand with a partial destruction of the crystal structure in these cases, the catalytic properties suffer. To ensure an intact surface structure, and thus the excellent catalytic properties, a bottom up approach for the synthesis of Pd-Ga intermetallic compounds in a nanoparticulate state has been developed recently [47]. Physically supporting the particles on $\gamma-\mathrm{Al}_{2} \mathrm{O}_{3}$ after the synthesis results in highly selective and very stable catalysts, which show even higher activities than conventional supported Pd-catalysts (Fig. 7).

As an alternative and due to the less difficult synthesis a more feasible approach, we studied co-reduction of $\mathrm{PdO}-\mathrm{Ga}_{2} \mathrm{O}_{3}$ mixtures, prepared by impregnation of commercial $\mathrm{Ga}_{2} \mathrm{O}_{3}$ with $\mathrm{Pd}$ acetate solution followed by calcination at $773 \mathrm{~K}$. It has been elaborated above and reported in literature [66], that hydrogen reduction of $\mathrm{Pd} / \mathrm{Ga}_{2} \mathrm{O}_{3}$ may lead to the formation of $\mathrm{Pd}-\mathrm{Ga}$ intermetallic compounds. In the following, FTIR spectroscopy of $\mathrm{CO}$ adsorption is utilized to investigate and contrast the adsorption sites available on $\mathrm{Pd}$ and $\mathrm{Pd}_{\mathrm{x}} \mathrm{Ga}_{\mathrm{y}}$ particles prepared by reduction at temperatures of 298 and $673 \mathrm{~K}$, respectively. Furthermore, in order to examine a possible influence of the support, we compared $\mathrm{Pd}$ nanoparticles supported on a nonreducible oxide $\left(\mathrm{Al}_{2} \mathrm{O}_{3}\right)$ with those on a reducible oxide support $\left(\mathrm{Ga}_{2} \mathrm{O}_{3}\right)$, employing vibrational spectroscopy of $\mathrm{CO}$ adsorption after reduction at different temperatures. The mean $\mathrm{Pd}$ particle size, as determined by $\mathrm{CO}$ and $\mathrm{H}_{2}$ chemisorption and by HRTEM, was about $4.5 \mathrm{~nm}$ for $\mathrm{Pd} / \mathrm{Al}_{2} \mathrm{O}_{3}$ and around $4 \mathrm{~nm}$ for $\mathrm{Pd} / \mathrm{Ga}_{2} \mathrm{O}_{3}$ (for details see [68] and [69]).

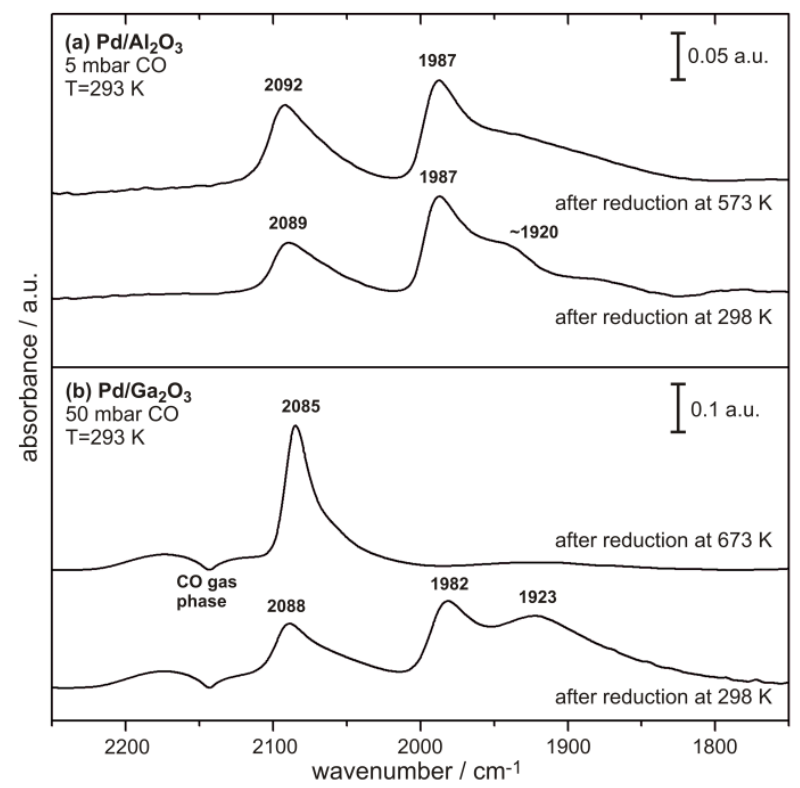

Figure 13: Infrared spectra of $\mathrm{CO}$ adsorbed on (a) $\mathrm{Pd} / \mathrm{Al}_{2} \mathrm{O}_{3}$ and (b) $\mathrm{Pd} / \mathrm{Ga}_{2} \mathrm{O}_{3}$ catalysts, following $\mathrm{H}_{2}$ reduction at room- and elevated temperature.

Spectra of $\mathrm{CO}$ adsorption on the $2 \mathrm{wt} \% \mathrm{Pd} / \mathrm{Al}_{2} \mathrm{O}_{3}$ catalyst after reduction at room temperature and at elevated temperature (573 $\mathrm{K})$ are shown in Figure 13. The spectra of adsorbed CO were basically identical in terms of intensity and frequency, irrespective of the reduction temperature (Fig. 10a). In 5 mbar CO three vibrational resonances were observed, at $\sim 1920 \mathrm{~cm}^{-1}, \sim 1987$ $\mathrm{cm}^{-1}$ and $\sim 2090 \mathrm{~cm}^{-1}$. These peaks are characteristic of hollow or bridge bonded $\mathrm{CO}$ on (111) facets of pure $\mathrm{Pd}$, of bridge bonded 
CO on edges/steps or (100) facets, and of on-top bonded CO, respectively [70,71].

Corresponding IR spectra of $\mathrm{CO}$ adsorption on $\mathrm{Pd} / \mathrm{Ga}_{2} \mathrm{O}_{3}$ are displayed in Figure 13b, again after different reduction temperatures. Bands typical of $\mathrm{CO}$ adsorbed on metallic $\mathrm{Pd}$ were detected after room temperature reduction, similar to the $\mathrm{Pd} / \mathrm{Al}_{2} \mathrm{O}_{3}$ catalyst. However, increasing reduction temperatures decreased the intensity of bridge- and multiply bonded $\mathrm{CO}$, which nearly completely disappeared after reduction at $673 \mathrm{~K}$ in hydrogen. This clearly indicated an isolation of $\mathrm{Pd}$ atoms by the formation of a Pd-Ga alloy or intermetallic compound. The band of $\mathrm{CO}$ adsorbed linearly on (isolated) $\mathrm{Pd}$ atoms of $\mathrm{Pd}_{\mathrm{x}} \mathrm{Ga}_{\mathrm{y}} / \mathrm{Ga}_{2} \mathrm{O}_{3}$ appeared at $2085 \mathrm{~cm}^{-1}$.

The phase and composition of the intermetallic compound formed upon reduction of the $\mathrm{Pd} / \mathrm{Ga}_{2} \mathrm{O}_{3}$ powder catalyst was determined by $\mathrm{X}$-ray diffraction performed in situ during heating in a flow of $25 \% \mathrm{H}_{2}$ in $\mathrm{He}$ (Fig. 14). Reflections assigned to the crystalline $\beta-\mathrm{Ga}_{2} \mathrm{O}_{3}$ support remained unchanged, regardless of temperature. At temperatures from 398 to $523 \mathrm{~K}$ the (111) reflection of $\mathrm{Pd}$ metal at $2 \theta=40.2^{\circ}$ was additionally observed. Below $398 \mathrm{~K}$ the $\beta$-palladiumhydride phase was present, thus no $\mathrm{Pd}$ metal reflection was observed (diffractogram not shown). At $673 \mathrm{~K}$ reflections at $2 \theta=44.6,41.2,40.1$ and $39.7^{\circ}$ were detected that can be assigned to the $\mathrm{Pd}_{2} \mathrm{Ga}$ phase [72], which does not form a hydride phase [73].

By combining the information obtained by in situ XRD on the bulk structure with the surface-sensitive information from FTIR spectroscopy, we were able to follow the formation of the intermetallic compound in detail. Activation of hydrogen occurs on $\mathrm{Pd}$ and hydrogen spillover to $\mathrm{Ga}_{2} \mathrm{O}_{3}$ leads to (partial) support reduction and intermetallic compound formation. Such a promotional reduction effect of the noble metal through hydrogen spillover from metallic palladium has also been suggested by Collins et al. [74] for $\mathrm{Ga}-\mathrm{Pd} / \mathrm{SiO}_{2}$ catalysts. A more detailed study [69] on the temperature range of intermetallic formation indicated surface modifications occurring at temperatures significantly lower than those needed for the formation of crystalline $\mathrm{Pd}_{2} \mathrm{Ga}$.

It is interesting to note that, upon CO chemisorption, a single, though slightly structured band indicating the presence of a single type of adsorption site was also observed for the unsupported metallurgical PdGa model sample (see above) [41]. In this case it was detected at $2047 \mathrm{~cm}^{-1}$ and did not show any partial pressure dependence. Taking the results of the $\mathrm{CO}$ chemisorption experiments obtained on this PdGa model sample and on the nano- $\mathrm{Pd}_{2} \mathrm{Ga} / \mathrm{Ga}_{2} \mathrm{O}_{3}$ powder sample into account, it can be concluded that the adsorption properties are similar for $\mathrm{PdGa}$ as well as for $\mathrm{Pd}_{2} \mathrm{Ga}$ with respect to the absence of multiply bonded $\mathrm{CO}$ and, thus, strongly modified compared to pure $\mathrm{Pd}$. The frequency of on-top $\mathrm{CO}$ on $\mathrm{Pd}_{2} \mathrm{Ga}$ was only slightly shifted to lower wavenumber compared to (pure) Pd nanoparticles, despite intermetallic compound formation. In contrast, other bimetallic alloys (such as $\mathrm{PdZn}$ or $\mathrm{PdAg}$ ) induce red shifts of up to 20-40 $\mathrm{cm}^{-1}$, originating from the increased backdonation from $\mathrm{Pd} \mathrm{d}$ bands to $\mathrm{CO}$ and a concomitant weakening of the internal $\mathrm{C}-\mathrm{O}$ bond $[75,76]$. For the "Pd-rich" $\mathrm{Pd}_{2} \mathrm{Ga}$ system, the effect of intermetallic formation is mainly manifest by decreasing the $\mathrm{CO}$ binding energy on bridging and hollow sites, but only a minor effect on the on-top C-O stretching frequency was observed. The destabilisation of bridging and hollow sites is presumably due to the increased Pd-Pd interatomic distances [72] and the amount of
$\mathrm{Ga}$ in $\mathrm{Pd}_{2} \mathrm{Ga}$ is apparently sufficient to induce the desired "site isolation". For the (unsupported) PdGa system, apart from site isolation, the electronic interaction is more pronounced, leading to an on-top CO frequency as low as $2047 \mathrm{~cm}^{-1}$. The exact influence of particle size [77], $\mathrm{Pd}: \mathrm{Ga}$ ratio and of the oxide support on vibrational frequencies of adsorbed $\mathrm{CO}$ should, however, be examined in more detail.

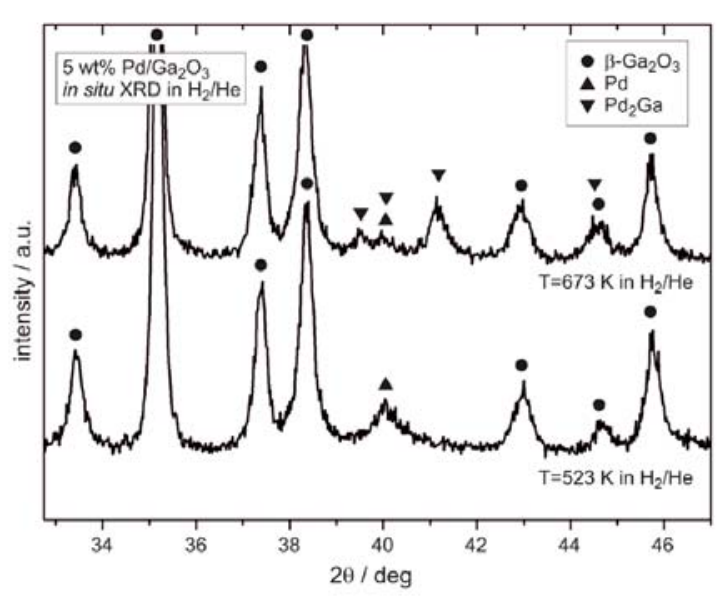

Figure 14: X-ray diffractograms recorded in situ at the indicated temperatures during reduction in 25 vol\% $\mathrm{H}_{2}$ in He. Reflections at $2 \theta=40.2^{\circ}$ correspond to $\mathrm{Pd}$ metal $(\boldsymbol{\Delta})$, reflections at $2 \theta=44.6,41.2,40.1$ and $39.7^{\circ}$ are assigned to the intermetallic compound $\mathrm{Pd}_{2} \mathrm{Ga}(\boldsymbol{\nabla})$. All other reflexes can be assigned to the $\beta$ $\mathrm{Ga}_{2} \mathrm{O}_{3}$ support $(\bullet)$

Another promising approach for the preparation of supported $\mathrm{Pd}_{2} \mathrm{Ga}$ catalysts comprises co-precipitation of aqueous solutions $\mathrm{Pd}^{2+}$ and $\mathrm{Ga}^{3+}$ to form a well-defined precursor material with both ionic species in a joint cationic lattice. Layered double hydroxides (LDH) of the general composition $\mathrm{Pd}_{x} \mathrm{Mg}_{0.7-x} \mathrm{Ga}_{0.3}(\mathrm{OH})_{2}\left(\mathrm{CO}_{3}\right)_{0.15}$. $m \mathrm{H}_{2} \mathrm{O}(0 \leq x \leq 0.025)$ can be used as they allow a close interaction of $\mathrm{Pd}$ and $\mathrm{Ga}$ species [78]. The LDH precursors were synthesized under $\mathrm{pH}$ controlled conditions and by thermal decomposition and reduction in hydrogen at $823 \mathrm{~K}$ intermetallic $\mathrm{Pd}_{2} \mathrm{Ga}$ nanoparticles $(7 \mathrm{~nm})$ supported on porous $\mathrm{MgO} / \mathrm{MgGa}_{2} \mathrm{O}_{4}$ oxide matrix were obtained. The intermetallic phase formation was evidenced by HRTEM and XPS, while XRD could not provide detailed insights due to the small particle size and low loading. Reaction of Pd with Ga lead to an increased binding energy of the $\mathrm{Pd} 3 \mathrm{~d}_{5 / 2}$ signal to $336.1 \mathrm{eV}$ (Fig 15). The high binding energy is likely a convolutional effect of the modified electronic structure of $\mathrm{Pd}_{2} \mathrm{Ga}$ and a final state particle size effect. Catalytic tests in the semi-hydrogenation of acetylene at conditions similar to those of Figure 7 revealed that the nano- $\mathrm{Pd}_{2} \mathrm{Ga}$ catalyst reached the high selectivity known from the unsupported bulk model sample indicating structural integrity of the intermetallic compound in the $\mathrm{LDH}$-derived material. As a result of nanosizing, the catalytic activity after a slow activation period at the beginning of the reaction was more than 5000 higher than that of the unsupported model catalyst. Thus, the catalytic properties related to the crystal and electronic structure of the intermetallic compound were successfully transferred from well-defined macroscopic model system to a nanostructured high performance system. 

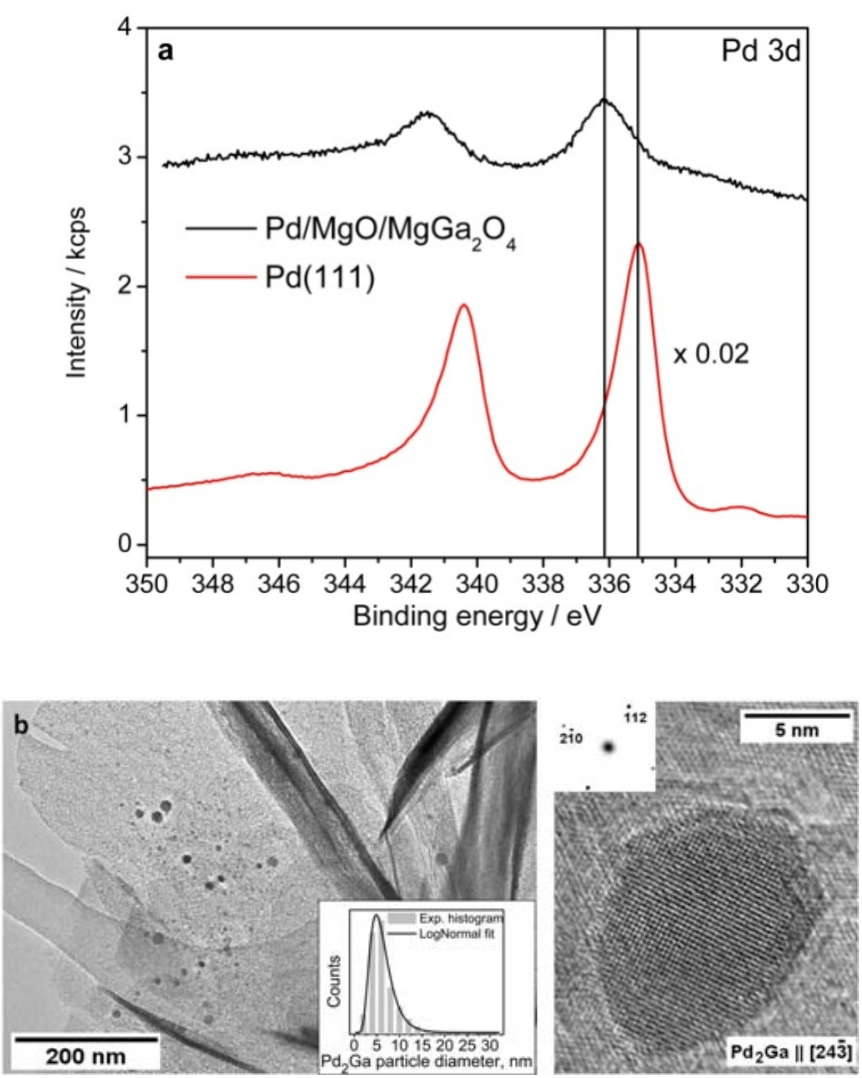

Figure 15: $\mathrm{XP}$ spectra of a $\mathrm{Pd} \mathrm{d}_{2} \mathrm{Ga} / \mathrm{MgO} / \mathrm{MgGa}_{2} \mathrm{O}_{4}$ catalyst obtained from PdMgGa-LDH precursor and a monometallic Pd single crystal [78]. The shift in the Pd $3 \mathrm{~d}$ binding energy of the catalyst compared to Pd metal indicates formation of an intermetallic compound (a). TEM investigation revealed the presence of $\mathrm{Pd}_{2} \mathrm{Ga}$ with a particle size of approximately $7 \mathrm{~nm}$ (b).

Also co-impregnation of $\mathrm{Pd}^{2+}$ and $\mathrm{Ga}^{3+}$ species on carbon nanotubes (CNTs) can be used to synthesize nanocrystalline $\mathrm{Pd}_{2} \mathrm{Ga}$ intermetallic catalysts, which are active and selective in acetylene hydrogenation [79]. Oxidized vacancies and localized double bonds on CNTs inhibit sintering and loss of the $\mathrm{Pd}_{2} \mathrm{Ga}$ nanoparticles during reactions. These nanocrystalline intermetallics possess abundant low coordination sites (edge, steps and kinks, Fig. 16) on their surface, thereby render a high activity. The surface and structure of obtained $\mathrm{Pd}_{2} \mathrm{Ga}$ nanoparticles were found to be thermally stable under reaction conditions. The approach of nanosizing intermetallics onto CNTs while obtaining good control of crystallite size may be applicable for synthesizing and supporting other nanocrystalline intermetallics.

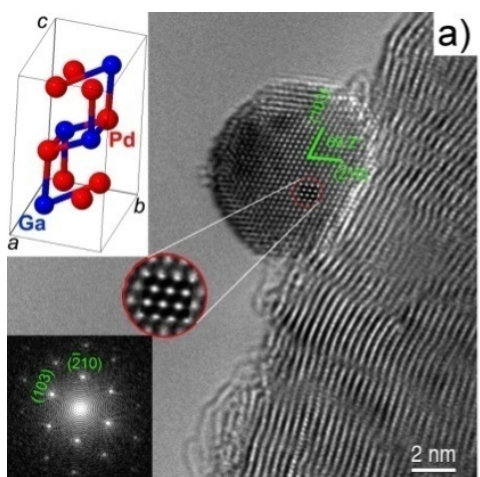

a)

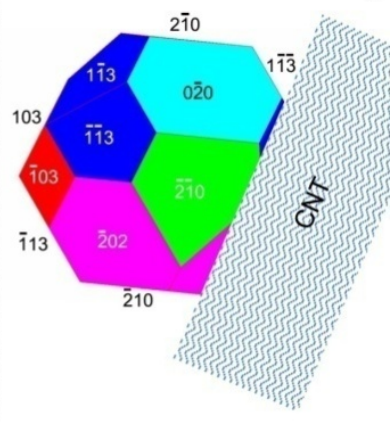

Figure 16. Microstructure characterizations of the $\mathrm{Pd}_{2} \mathrm{Ga} / \mathrm{CNT}$. a), HRTEM image, with the insets of (top) crystallographic model of $\mathrm{Pd}_{2} \mathrm{Ga}$ and (bottom) the Fast Fourier Transform of the local HRTEM image. The circled area represents the image simulation, conditioned at defocus of $6 \mathrm{~nm}$ and thickness of $6.1 \mathrm{~nm}$ viewed along the $<361>$ direction of $\mathrm{Pd}_{2} \mathrm{Ga}$. b), The Wulff constructions of the corresponding $\mathrm{Pd}_{2} \mathrm{Ga}$ nanoparticle in a).

In summary, $\mathrm{Ga}_{2} \mathrm{O}_{3}$-containing powders are interesting $\mathrm{Ga}$ sources for preparation of supported $\mathrm{Pd}_{2} \mathrm{Ga}$ nanoparticles, which can be obtained by hydrogen reduction of $\mathrm{Pd} / \mathrm{Ga}_{2} \mathrm{O}_{3}$ samples following an $\mathrm{H}$-spillover mechanism. This reaction displays a promising route for feasible preparation of high performance Pd$\mathrm{Ga}$ intermetallic compound catalysts.

\section{Discussion}

This work has shown that substantial aggregation of knowledge can be achieved through a collaborative effort addressing in a coordinated way various aspects of the catalytic function of an element. Many aspects were studied before in the substantial literature. Additional insight by targeted experiments and the application of high-level theory allowed joining together many pieces of the puzzle of selectivity control of Pd under high pressure operation conditions.

The following statements assume that mild reaction conditions are applied that allow for the existence of Pd hydrides. $\mathrm{Pd}$ is a potent hydrogenation catalyst when its ability to adsorb hydrogen on its surface is augmented by access of the subsurface regime to hydrogen. This access can be kinetically hindered by using macrocrystals of $\mathrm{Pd}$ without grain boundaries. It may also be inhibited by blocking the access of hydrogen at defects through accidental carbon deposits or through intended modifiers such as $\mathrm{Pb}$ or sulfur-containing modifiers. In all these cases, Pd's ability to hydrogenate carbon-carbon double bonds is severely diminished. If, however, Pd can be converted to a combination of a sub-surface hydride with surface-adsorbed atomic hydrogen, then the element is a highly active catalyst that can operate in a sustained way as the chemical potential of active hydrogen counteracts the tendency of $\mathrm{Pd}$ to dehydrogenate organic molecules to carbonaceous overlayers that were frequently studied in surface science and high pressure situations.

The chemical potential of carbon over Pd is enhanced when alkyne substrates are to be hydrogenated. This class of highly activated molecules can dissolve as carbon in the surface-near volume of $\mathrm{Pd}$ without necessarily forming a bulk carbide compound. This carbon "alloy" gives rise to a modified surface electronic structure reducing the bond strength of adsorbed hydrogen and thus lowering its surface concentration. Even more 
important is the site blocking action of the dissolved carbon for exchange processes of hydrogen with the Pd bulk: the formation of hydride is inhibited as long as the chemical potential of hydrogen does not exceed a critical value above which the hydrogen is able to gasify the dissolved carbon into volatile compounds and thus de-block the Pd catalyst bulk. In the carbonmodified state $\mathrm{Pd}$ is a weaker hydrogenation catalyst exhibiting excellent selectivity to semihydrogenation with a strong suppression of over-hydrogenation.

As no stoichiometric $\mathrm{Pd}$-carbide phases exist, the selective hydrogenation form occurs in situ with some influence of the nature of the $\mathrm{Pd}$ on the kinetics of the carbon dissolution process. Very large grains, small clusters and strained particles on strongly interacting supports are less susceptible to carbon dissolution whereas medium-sized Pd nanoparticles above 1-2 nm supported on weakly straining supports such as carbon or carbonates are highly reactive. The kinetics of formation of the selective phase by substrate dehydrogenation and decomposition will further depend on the competition between carbon dissolution into the subsurface on one hand and formation of carbonaceous deposits covering the surface as well as re-hydrogenation of surface carbon species to gas phase species. The exact pre-history of the catalyst or the presence of solvents will also affect the dynamical transformation of pure non-selective Pd.

A narrow window of selective operation exists thus for the dynamical selective form of the $\mathrm{Pd}$ catalysts that is given by material properties such as microstructure of the catalyst and the thermodynamic conditions of the reaction. Both the chemical potentials of hydrogen and of hydrocarbon substrates (and solvents) define the boundaries of the window making it difficult to control in real catalytic applications. It gets smaller when the reaction conditions are very mild or harsh with respect to the existence of hydrides. It gets wider when the carbon potential is high for dissolution and low for surface polymerization.

This sensitivity of selective hydrogenation on a critical choice of reaction conditions prompted the development of a designed barrier against hydride formation under a wider range of reaction conditions. Alloying changes the electronic structure by shifting the d-band to lower energies and by reducing the density of states at the Fermi level. This is required to less efficiently activate and bind hydrogen. Many alloys however will not stay intact and thus segregate and/or phase separate in reaction conditions [80]. Typical examples of such systems are the technical semihydrogenation catalyst for acetylene $\mathrm{Pd}-\mathrm{Ag}$ and compounds in the $\mathrm{Pd}-\mathrm{Zn}$ or $\mathrm{Pd}-\mathrm{Si}$ systems. It is noted that the very limited stability of the carbon-modified selective state of $\mathrm{Pd}$ follows exactly this scheme of sub-surface driven destabilization of the Pd-C system in accordance with the theoretical results described above.

In this situation a strongly covalent interaction between $\mathrm{Pd}$ and a second element as present in intermetallic compounds is a suitable solution as then no kinetic lowering of the segregation barrier can work. Such strongly stabilized compounds are $\mathrm{Pd}_{3} \mathrm{Ga}_{7}$ $\mathrm{PdGa}$ and $\mathrm{Pd}_{2} \mathrm{Ga}$. Our work shows that not only well-structured macroscopic bulk alloy samples but also nanoparticles supported on oxides or carbon retain their chemical stability against hydride formation under reduction conditions. Under the conditions of our semihydrogenation test the novel intermetallic compound-derived catalysts exhibit excellent performance data. This experimental observation is in broad agreement with theoretical predictions using scaling laws for selecting selective semihydrogenation catalysts. For intermetallic compounds like PdGa, care has to be taken, however, to take the theoretical predictions of electronic structure modifiers too literally, if the calculations are based on simplified statistical fcc alloys. Issues of crystal structure, bonding situation and chemical complexity of the terminating surface deviating much from the model bulk structure can greatly modify the reactivity and stability of such "artificial" Pd systems.

When going from our model conditions to the technically much milder conditions and when using the Pd-Ga intermetallic compounds in liquid phase hydrogenation the performance results are less attractive. This unusual behavior of reduced performance at milder reaction conditions needs some reasoning. The prize to pay for the deliberate modification of the electronic structure of $\mathrm{Pd}$ through forming a well-ordered intermetallic compound is an enormous increase in the structural complexity of the surface termination. Not only different orientations of terminating facets but also chemically different compositions of a class of terminations with the same orientation can and will occur when forming the surface of a covalent compound. In addition, the high oxophilicity of the $\mathrm{Ga}$ component leads to a large variety of possible $\mathrm{Ga}$ oxide-contaminated surfaces of $\mathrm{Pd}-\mathrm{Ga}$ systems formed by a reversal of the reactive alloying used for its synthesis Amongst them there are also varieties where a full Pd monolayer terminates the intermetallic compound. Catalytically such terminations are obviously not much different from pure Pd.

\section{Conclusion and Outlook}

In the present study, we identify the unintended or intentional control of the hydrogenation activity and selectivity of polycrystalline $\mathrm{Pd}$ by modifier atoms in the sub-surface volume of $\mathrm{Pd}$. These results show how sub-surface compound formation can be developed into a design tool for catalyst development. In addition to the nature of the modifier atom, also nanostructuring through particle size and metal-support interaction can kinetically control the reactivity of $\mathrm{Pd}$ with species in the subsurface. Thus, more detailed studies of structure and dynamics of the catalystreactant interaction are desirable to gain insight into the mutual interactions of catalyst and substrate and to develop synthetic strategies to influence the chemical complexity in the desired way It will be in particular interesting to use the concept of intermetallic compound formation that here has been introduced for the example of $\mathrm{PdGa}$ as a guideline to explore other binary and ternary systems and to develop effective and selective hydrogenation catalysts. The benefit of such efforts will be that we better understand the modes of selectivity control and can adequately adapt our reaction conditions and catalyst selection procedures.

\section{Acknowledgements}

Some authors acknowledge funding in the framework of the ATHENA project. The majority of the research teams actively used the ambient pressure XPS facilities at Bessy-II. HZB Berlin is acknowledged for allocation of beamtime and the ISISS team is acknowledged for substantial technical support of the measurements. Fruitful meetings of the consortium ("Pd-Days") have been hosted by the Max-Planck-Society, the University Innsbruck, the Technical University of Vienna and EMPA. All 
participants of the Pd-Days are acknowledged for openly sharing their views and results and for fruitful discussions. Some of the authors acknowledge funding by the Austrian Science Fund (FWF), Project P20892-N19.

Keywords: Selective hydrogenation - Palladium • Intermetallic compound • Carbon • Gallium

[1] A. Borodziński, G. C. Bond, Catal. Rev. 2006, 48, 91.

[2] A. Borodziński, G. C. Bond, Catal. Rev. 2008, 50, 379.

[3] G. C. Bond, G. Webb, P. B. Wells, J. M. Winterbottom, J. Catal. 1962, 1, 74.

[4] A. S. Al-Ammar, G. Webb, J. Chem. Soc. Faraday Trans. 1977, 74, 5195

[5] A. D. Johnson, S. P. Daley, A. L. Utz, S. T. Ceyer, Science 1992, 257, 223.

[6] V. Ledentu, W. Dong, P. Sautet, J. Am. Chem. Soc. 2000, 122, 1796.

[7] A. Michaelidis, P. Hu, A. Alavi, J. Chem. Phys. 1999, 111, 1343.

[8] N. A. Khan, S. Shaikhutdinov, H.-J. Freund, Catal. Lett. 2006, 108, 159

[9] M. Wilde, K. Fukutani, W. Ludwig, B. Brandt, J.-H. Fischer, S. Schauermann, H.-J. Freund, Angew. Chem. Int. Ed. 2008, 47, 9289.

[10] A. M. Doyle, S. K. Shaikhutdinov, H.-J. Freund, J. Catal. 2004, 223, 444.

[11] S. K. Shaikhutdinov, M. Heemeier, M. Bäumer, T. Lear, D. Lennon, R. J. Oldman, S. D. Jackson, H.-J. Freund, J. Catal. 2001, 200, 330.

[12] S. K. Shaikhutdinov, M. Frank, M. Bäumer, S. D. Jackson, R. J. Oldman J. C. Hemminger, H.-J. Freund, Catal. Lett. 2002, 80, 115

[13] B. Bridier, N. López. J. Pérez-Ramírez, Dalton Trans. 2010, 39, 8412 8419

[14] Battiston, G.C., Dalloro, L., Tauszik, G.R., Appl. Catal. 1982, 2, 1-17.

[15] M. García-Mota, B. Bridier, J. Pérez-Ramírez, N. López, J. Catal. 2010 273, 92-102.

[16] Á. Molnár, S. Sárkány, M. Varga, J. Mol. Catal. A 2001, 173, 185.

[17] G. C. Bond, P. B. Wells, J. Catal. 1966, 5, 65

[18] S. Gonzalez, K. M. Neyman, S. Shaikhutdinov, H. J. Freund, F. Illas, J. Phys. Chem. C 2007, 111, 6852-6856.

[19] F. Studt, F. Abild-Pedersen, T. Bligaard, R. Z. Sørensen, C. H. Christensen, J. K. Nørskov, Science 2008, 320, 1320.

[20] P. Tiruppathi, J.J. Low, A.S.Y. Chan, S.R. Bare, R.J. Meyer, Catal. Today 2011, 165, 106-111.

[21] N. López, C. Vargas-Fuentes, Chem. Commun. 2012, 48, 1379-1391

[22] N. G. Connelly, T. Damhus, R. M. Hartshorn, A. T. Hutton, Nomenclature of Inorganic Chemistry - IUPAC Recommendations 2005, The Royal Society of Chemistry: Cambridge, 2005.

[23] D. Teschner, E. M. Vass, M. Hävecker, S. Zafeiratos, P. Schnörch, H Sauer, A. Knop-Gericke, R. Schlögl, M. Chamam, A. Wootsch, A. S. Canning, J. J. Gamman, S. D. Jackson, J. McGregor, L. F. Gladden, J. Catal. 2006, 242, 16.

[24] D. Teschner, J. Borsodi, A. Wootsch, Zs. Révay, M. Hävecker, A. KnopGericke, S. D. Jackson, R. Schlögl, Science 2008, 320, 86.

[25] D. Teschner, Zs. Révay, J. Borsodi, M. Hävecker, A. Knop-Gericke, R. Schlögl, D. Milroy, S. D. Jackson, D. Torres, P. Sautet, Angew. Chem. Int. Ed. 2008, 47, 9274.

[26] B. Bridier, J. Pérez-Ramírez, J. Catal. 2011, 284, 165-175.

[27] Zs. Révay, T. Belgya, L. Szentmiklósi, Z. Kis, A. Wootsch, D. Teschner, M. Swoboda, R. Schlögl, J. Borsodi, R. Zepernick, Anal. Chem. 2008, 80 6066 .

[28] D. Teschner, J. Borsodi, Z. Kis, L. Szentmiklosi, Zs. Revay, A. KnopGericke, R. Schlögl, D. Torres, P. Sautet, J. Phys. Chem. C 2010, 114 2293

[29] N. Seriani, F. Mittendorfer, G. Kresse, J. Chem. Phys. 2010, 132, 024711.

[30] P. Sautet, F. Cinquini, ChemCatChem 2010, 2, 636.

[31] J. Greeley, M. Mavrikakis, J. Phys. Chem. B 2005, 109, 3460.

[32] W. Dong, V. Ledentu, P. Sautet, A. Eichler, J. Hafner, Surf. Sci. 1998 $411,123$.

[33] K. Kovnir, M. Armbrüster, D. Teschner, T. V. Venkov, F. C. Jentoft, A Knop-Gericke, Yu. Grin, R. Schlögl, Sci. Technol. Adv. Mater. 2007, 8 420.

[34] Kohlmann, H. in Encyclopedia of Physical Science and Technology, Vol. 9 (Ed: R. A. Meyers), Academic Press, San Diego, 2002, 441-458.

[35] M. Klanjšek, A. Gradišek, A. Kocjan, M. Bobnar, P. Jeglič, M. Wencka, Z. Jagličić, P. Popčević, J. Ivkov, A. Smontara, P. Gille, M. Armbrüster, Yu. Grin, J. Dolinšek, J. Phys. Cond. Mat. 2011, submitted.
[36] M. Armbrüster, R. Giedigkeit, A. Ormeci, W. Schnelle, F. R. Wagner, A Rabis, M. Baenitz, Yu. Grin, Chem. Mater. 2011, in preparation.

[37] M. Armbrüster in Encyclopedia of Catalysis, (Ed: I.T. Horvath), Online Edition, Wiley, 2011, DOI: 10.1002/0471227617.

[38] K. Khalaff, K. Schubert, J. Less-Common Met. 1974, 37, 129

[39] M. Armbrüster, R. Giedigkeit, H. Borrmann, in preparation. OR R. Giedigkeit, PhD Thesis, Technical University of Dresden (2007).

[40] J. Osswald, R. Giedigkeit, R. E. Jentoft, M. Armbrüster, F. Girgsdies, K. Kovnir, T. Ressler, Yu. Grin, R. Schlögl, J. Catal. 2008, 258, 210.

[41] K. Kovnir, M. Armbrüster, D. Teschner, T. Venkov, L. Szentmiklósi, F. C. Jentoft, A. Knop-Gericke, Yu. Grin, R. Schlögl, Surf. Sci. 2009, 603, 1784.

[42] K. Kovnir, D. Teschner, M. Armbrüster, P. Schnörch, M. Hävecker, A. Knop-Gericke, Yu. Grin, R. Schlögl, BESSY Highlights 2007 2008, 22.

[43] A. F. Al Alam, S. F. Matar, M. Nakhl, N. Quaini, Sol. State Sci. 2009, 11 1098

[44] J. Osswald, K. Kovnir, M. Armbrüster, R. Giedigkeit, R. E. Jentoft, U. Wild, Yu. Grin, R. Schlögl, J. Catal. 2008, 258, 219.

[45] K. Kovnir, J. Osswald, M. Armbrüster, D. Teschner, G. Weinberg, U. Wild, A. Knop-Gericke, T. Ressler, Yu. Grin, R. Schlögl, J. Catal. 2009, 264, 93

[46] M. Armbrüster, M. Schmidt, K. Kovnir, M. Friedrich, K. Weinhold, Yu. Grin, R. Schlögl, European Patent Application, EP07018368, 2007.

[47] M. Armbrüster, G. Wowsnick, M. Friedrich, M. Heggen, R. Cardoso-Gil, J. Am. Chem. Soc. 2011, 133, 9112-9118.

[48] H. Lindlar, Helv. Chim. Acta $1952,57,446-450$.

[49] W. Palczewska, A. Jablnski Z. Kaszkur, J. Mol. Catal. 1984, 25, 307-316.

[50] M. Garciá-Mota, J. Gómez-Díaz, G. Novell-Leruth, C. Vargas-Fuentes, L. Bellarosa, B. Bridier, J. Pérez-Ramírez, N. López, Theor. Chem. Acc. 2011, 128, 663-673.

[51] R. Schlögl, K. Noack, H. Zbinden, Helv. Chim. Acta 1987, 70, 627-679.

[52] G. A. Somorjai, Science 1985, 227, 902.

[53] G. Rupprechter, Adv. Catal. 2007, 51, 133.

[54] a) H.-J. Freund, N. Ernst, T. Risse, H. Hamann, G. Rupprechter, phys. stat. sol. (a) 2001, 187, 257; b) G. Ertl, H.-J. Freund, Physics Today 1999, 52, 32; c) H.-J. Freund, M. Bäumer, H. Kuhlenbeck, Adv. Catal. 2000, 45, 333.

[55] D. Rosenthal, R. Widmer, R. Wagner, P. Gille, M. Armbrüster, Yu. Grin, R. Schlögl, O. Gröning, submitted.

[56] R. Gaspari, PhD Thesis, Empa/ETH Zürich, 2012

[57] B. H. Verbeek, P. K. Larsen, W. M. Gerits, Vacuum 1983, 33, 813-4.

[58] B. Bridier, J. Pérez-Ramírez, A. Knop-Gericke, R. Schlögl D. Teschner, Chem. Sci. 2011, 2, 1379.

[59] G. Rupprechter, K. Hayek, L. Rendon, M. Jose-Yacaman, Thin Solid Films 1995, 260, 148.

[60] G. L. Haller, D. E. Resasco, Adv. Catal. 1989, 36, 173

[61] S. Penner, B. Jenewein, H. Gabasch, B. Klötzer, D. Wang, A. KnopGericke, R. Schlögl, K. Hayek, J. Catal. 2006, 241, 14.

[62] S. Penner, H. Lorenz, B. Klötzer, D. Wang, M. Stöger-Pollach, C Rameshan, W. Jochum, Appl. Catal. A 2009, 358, 193.

[63] H. Lorenz, S. Turner, O. Lebedev, G. van Tendeloo, K. Pfaller, C. Rameshan, B. Klötzer, S. Penner, Appl. Catal. A 2010, 374,180.

[64] B. Jenewein, S. Penner, H. Gabasch, B. Klötzer, D. Wang, A. KnopGericke, R. Schlögl, K. Hayek, J. Catal. 2006, 241, 155.

[65] S. Penner, B. Jenewein, K. Hayek, Catal. Lett. 2007, 113, 65.

[66] N. Iwasa, N. Takezawa, Top. Catal. 2003, 22, 215

[67] J. D. Holladay, Y. Wang, E. Jones, Chem. Rev. 2004, 104, 4767

[68] K. Föttinger, R. Schlögl, G. Rupprechter, Chem. Commun. 2008, 320

[69] A. Haghofer, K. Föttinger, F.Girgsdies, D. Teschner, A. Knop-Gericke, R. Schlögl, G. Rupprechter, J. Catal.2012, 286, 13-21.

[70] T. Lear, R. Marshall, J. A. Lopez-Sanchez, S. D. Jackson, T. M. Klapötke, G. Rupprechter, M. Bäumer, H.-J. Freund, D. Lennon, J. Chem. Phys. 2005, 123, 174706

[71] T. Dellwig, J. Hartmann, J. Libuda, I. Meusel, G. Rupprechter, H. Unterhalt, H.-J. Freund, J. Mol. Catal. A 2000, 162, 51

[72] K. Kovnir, M. Schmidt, C. Waurisch, M. Armbrüster, Yu. Prots, Yu. Grin, Z. Krist. 2008, 223, 7.

[73] H. Kohlmann, J.Solid State Chem. 2010, 183, 367-372.

[74] S. E. Collins, M. L. Baltanas, J. L. Garcia Fierro, A. L. Bonivardi, J. Catal. 2002, 211, 252

[75] K. Föttinger, J. A. van Bokhoven, M. Nachtegaal, G. Rupprechter, J. Phys. Chem. Lett. 2011, 2, 428.

[76] C. Rameshan, W. Stadlmayr, C. Weilach, S. Penner, H. Lorenz, M. Hävecker, R. Blume, T. Rocha, D. Teschner, A. Knop-Gericke, R. Schlögl, N. Memmel, D. Zemlyanov, G. Rupprechter, B. Klötzer, Angew. Chem. Int. Ed. 2010, 49, 3224. 
[77] J. Silvestre-Albero, G. Rupprechter, H.-J. Freund, J. Catal. 2006, 240, 58-65.

[78] A. Ota, M. Armbrüster, M. Behrens, D. Rosenthal, M. Friedrich, I. Kasatkin, F. Girgsdies, W. Zhang, R. Wagner, R. Schlögl J. Phys. Chem. C 2011, 115, 1368-1374.
[79] L. Shao, W. Zhang, M. Armbrüster, D. Teschner, F. Girgsdies, B. Zhang, O. Timpe, M. Friedrich, R. Schlögl, D. S. Su, Angew. Chem. Int. Ed. 2011, 50, 10231-10235.

[80] S. Zafeiratos, S. Piccinin, D. Teschner, Catal. Sci. Technol. 2012 DOI: 10.1039/c2cy00487a. 
Entry for the Table of Contents (Please choose one layout)

Layout 1:

\section{MINIREVIEW}

((Text for Table of Contents))

((Author(s), Corresponding Author(s)*)

Page No. - Page No.

((Title))

((Insert TOC Graphic here)) 